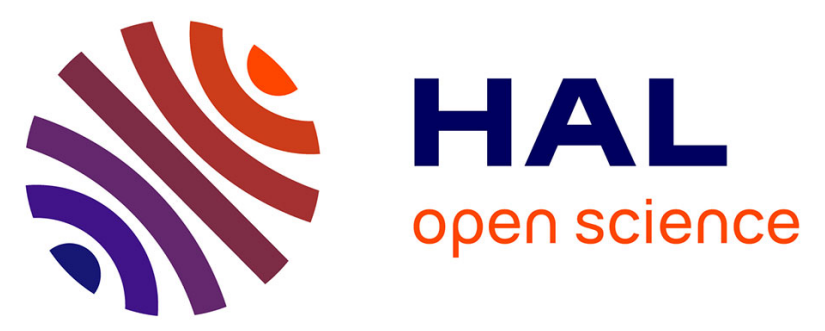

\title{
Hydrogen Bonding and Proton Transfer to the Trihydride Complex [Cp*MoH3(dppe)]: IR, NMR, and Theoretical Investigations
}

Natalia V Belkova, Pavel O Revin, Maria Besora, Miguel Baya, Lina M Epstein, Agustí Lledós, Rinaldo Poli, Elena S Shubina, Evgenii V Vorontsov

\section{To cite this version:}

Natalia V Belkova, Pavel O Revin, Maria Besora, Miguel Baya, Lina M Epstein, et al.. Hydrogen Bonding and Proton Transfer to the Trihydride Complex [Cp*MoH3(dppe)]: IR, NMR, and Theoretical Investigations. European Journal of Inorganic Chemistry, 2006, 2006 (11), pp.2192-2209. 10.1002/ejic.200600093 . hal-03196062

\section{HAL Id: hal-03196062 https://hal.science/hal-03196062}

Submitted on 12 Apr 2021

HAL is a multi-disciplinary open access archive for the deposit and dissemination of scientific research documents, whether they are published or not. The documents may come from teaching and research institutions in France or abroad, or from public or private research centers.
L'archive ouverte pluridisciplinaire HAL, est destinée au dépôt et à la diffusion de documents scientifiques de niveau recherche, publiés ou non, émanant des établissements d'enseignement et de recherche français ou étrangers, des laboratoires publics ou privés. 


\section{Hydrogen bonding and proton transfer to the trihydride complex [Cp*MoH3(dppe)]: IR, NMR, and theoretical investigations.}

Natalia V. Belkova,${ }^{[\mathrm{a}]}$ Pavel O. Revin, ${ }^{[\mathrm{a}]}$ Maria Besora, ${ }^{[\mathrm{b}]}$ Miguel Baya, ${ }^{[\mathrm{c}]}$ Lina M. Epstein, ${ }^{[\mathrm{a}]}$ Agustí Lledós, ${ }^{[\mathrm{b}] *}$ Rinaldo Poli, ${ }^{[\mathrm{c}] *}$ Elena S. Shubina, ${ }^{[\mathrm{a}] *}$ Evgenii V. Vorontsov ${ }^{[\mathrm{a}]}$

Laboratoire de Chimie de Coordination, UPR CNRS 8241, lié par convention à l'Université Paul Sabatier et à l'Institut national Polytechnique de Toulouse, 205 Route de Narbonne, 31077 Toulouse Cedex, France

Nesmeyanov Institute of Organoelement Compounds, Russian Academy of Sciences, Vavilov Street 28, 119991 Moscow, Russia

Departament de Química, Edifici Cn, Universitat Autónoma de Barcelona, 08193 Bellaterra, Spain.

[a] Dr. N.V. Belkova, Prof. L.M. Epstein, P.O. Revin, D.Sc. E.S. Shubina, Dr. E.V. Vorontsov: INEOS, Moscow, Russia. Fax: E-mail: shu@ineos.ac.ru.

[b] Dr. M. Besora, Prof. A. Lledós: UAB, Bellaterra, Spain. E-mail: agusti@klingon.uab.es.

[c] Dr. M. Baya, Prof. R. Poli: LCC, Toulouse, France. Fax: +33-561553003. E-mail: poli@1cc-toulouse.fr.

Keywords: Dihydrogen Bonding, Hydride Ligands, Molybdenum, Proton Transfer Mechanism, DFT Calculations 


\section{Abstract}

The interaction between $\left[\mathrm{Cp} * \mathrm{MoH}_{3}(\mathrm{dppe})\right]\left(\right.$ dppe $\left.=\mathrm{Ph}_{2} \mathrm{PCH}_{2} \mathrm{CH}_{2} \mathrm{PPh}_{2}\right)$ and a variety of proton donors has been investigated by a combination of experiments and DFT calculations. Weak proton donors (monofluoroethanol, MFE, and trifluoroethanol, TFE) allow the determination of basicity factor $\left(E_{j}=1.42 \pm 2\right)$ and thermodynamic parameters for the hydrogen bond formation $\left(\Delta \mathrm{H}_{\mathrm{HB}}=-4.9 \pm 0.2\right.$ and $-6.1 \pm 0.3 \mathrm{kcal} \mathrm{mol}^{-1} ; \Delta \mathrm{S}_{\mathrm{HB}}=-15.7 \pm 0.7$ and $-20.4 \pm 1$ for MFE and TFE, respectively). For TFE, a stable low-temperature proton transfer equilibrium $(220-240 \mathrm{~K})$ with the cationic classical tetrahydrido derivative $\left[\mathrm{Cp}^{*} \mathrm{MoH}_{4}(\mathrm{dppe})\right]^{+}$could be investigated independently by $\mathrm{UV}$-visible $\left(\Delta \mathrm{H}^{\circ}{ }_{\mathrm{PT}}=-2.8 \pm 0.4 \mathrm{kcal} \mathrm{mol}^{-1}\right.$ and $\Delta \mathrm{S}^{\circ}{ }_{\mathrm{PT}}=-15 \pm 2 \mathrm{cal}$ $\left.\mathrm{mol}^{-1} \mathrm{~K}^{-1}\right)$ and ${ }^{1} \mathrm{H} \mathrm{NMR}\left(\Delta \mathrm{H}^{\circ} \mathrm{PT}=-2.7 \pm 0.5 \mathrm{kcal} \mathrm{mol}^{-1}\right.$ and $\left.\Delta \mathrm{S}^{\circ}{ }_{\mathrm{PT}}=-11 \pm 2 \mathrm{cal} \mathrm{mol}^{-1} \mathrm{~K}^{-1}\right)$ spectroscopy. Upon warming, however, the tetrahydride evolves by dihydrogen loss and formation of a hydride-free diamagnetic product. Stronger proton donors (hexafluoroisopropanol, HFIP; $p$-nitrophenol, PNP; perfluoro-tert-butanol, PFTB; and $\mathrm{HBF}_{4} \cdot \mathrm{OEt}_{2}$ ), lead to more extensive proton transfer at lower donor/Mo ratios. A 1:1 proton transfer stoichiometry is indicated independently by a titration experiment with UV-visible monitoring for the $\left[\mathrm{Cp}^{*} \mathrm{MoH}_{3}(\mathrm{dppe})\right]-\mathrm{PNP}$ reaction, and by a stopped-flow kinetics investigation for the $\left[\mathrm{Cp} * \mathrm{MoH}_{3}(\mathrm{dppe})\right]-\mathrm{HFIP}$ reaction. For all proton transfer processes investigated, the classical tetrahydrido cation forms directly, without the observation of a nonclassical intermediate. DFT calculations have been carried out on the interaction between TFE and HFIP and the model compound $\left[\mathrm{CpMoH}_{3}(\mathrm{dpe})\right]$ (dpe $=\mathrm{H}_{2} \mathrm{PCH}_{2} \mathrm{CH}_{2} \mathrm{PH}_{2}$ ) both in the gas phase and in $\mathrm{CH}_{2} \mathrm{Cl}_{2}$ solvent with the polarizable continuum model and, to a more limited extent, on the full $\left[\mathrm{Cp}^{*} \mathrm{MoH}_{3}(\mathrm{dppe})\right]$ system. A detailed comparison of the observed and calculated frequency shifts for the M-H vibrations is presented. The calculations have explored the relative energy and geometry of various configurations involving either a hydride ligand or the 
metal as the principal proton accepting site. They have also probed two principal proton transfer pathways, leading to the unobserved nonclassical intermediate and to the observed classical product. From these studies, it appears that a nonclassical intermediate may be obtained by a kinetically controlled proton transfer to a hydride site, followed by an intramolecular rearrangement through a very low energy barrier. However, a competitive lowenergy pathway for direct proton transfer at the metal site is also revealed by the calculations. 


\section{Introduction}

Proton transfer processes to and from transition metal centers and hydride ligand sites continue to attract considerable research interest because of their fundamental importance for catalysis and in biochemistry. ${ }^{[1]}$ The kinetic preference for hydride $v s$. metal protonation is now quite firmly established, ${ }^{[2]}$ though exceptions have recently been reported from studies carried out in our laboratories. ${ }^{[3]}$ The proton transfer occurs via intermediates, for which characteristic spectroscopic signatures have been established, that contain hydrogen bonds between the proton donor and the proton acceptor (the metal center or a hydride ligand), see Scheme $1 .{ }^{[4]}$ The term "non-classical hydrogen bonding" has been coined to address these interactions, while $\mathrm{H}$-bonding specifically involving a hydride ligand has also been termed "dihydrogen bonding". [5] The relationship between the preferred thermodynamic site of hydrogen bonding (i.e. the relative energy of species $\mathbf{I}$ and $\mathbf{I V}$ ) and the kinetic site of proton transfer (i.e. the relative energy barrier leading to species II and $\mathbf{V}$ ) is of interest to us. We have recently presented combined experimental and theoretical results showing that the preferred hydrogen bonding site for compound $[\mathrm{Cp} * \mathrm{Fe}(\mathrm{dppe}) \mathrm{H}]$, i.e. the hydride site, corresponds to the site of preferred proton transfer. ${ }^{[6]}$ In parallel work, some of us have studied the mechanism of the hydride protonation, analyzing the influence of medium polarity and concentration effects, both experimentally and theoretically. ${ }^{[7]}$ We have demonstrated the involvement of ion pairs formed by cationic dihydrogen complexes and the anionic conjugate basis of the proton donor. In these studies the stabilizing role of the solvent and the homoconjugate anions $[\mathrm{A} \cdots \mathrm{H} \cdots \mathrm{A}]^{-}$in the protonation process has also been recognized. 
In order to determine the general relationship between the thermodynamics of hydrogen bonding to various possible sites and the energy barrier leading from each of these sites to proton transfer, a greater number of case studies is necessary, especially for polyhydride complexes where the hydride ligands occupy inequivalent positions so that it is also possible in principle to discriminate between different hydride sites. For this reason, we have selected compound $\left[\mathrm{Cp} * \mathrm{Mo}(\mathrm{dppe}) \mathrm{H}_{3}\right]$, which was synthesized in one of our laboratories a few years ago. ${ }^{[8]}$ In this system there are four basic potential sites (the metal and the three hydride ligands) able to establish hydrogen bonds with a proton donor. Moreover, several isomers could result from the proton transfer process. The X-ray structure of the trihydride compound was of sufficient quality to locate the hydride ligands and showed that they occupy two different sites as shown in Scheme 2. ${ }^{[9]}$ The geometry is best described as an ideal trigonal prism if the $\mathrm{Cp}^{*}$ ligand is considered to occupy a single position in correspondence to its ring centroid. However, the compound is highly fluxional and a single hydride resonance, which is split into a binomial triplet by the two equivalent $\mathrm{P}$ nuclei, remained sharp down to $183 \mathrm{~K} .^{[8]}$

\section{$<$ Scheme 2>}

Protonation studies have previously been carried out only with $\mathrm{HBF}_{4}$, leading to the formal product of metal protonation, the classical tetrahydride complex $\left[\mathrm{Cp}^{*} \mathrm{MoH}_{4}(\mathrm{dppe})\right]^{+}{ }^{[8]}$ However, this product is unstable and easily looses $\mathrm{H}_{2}$. It could be isolated upon low temperature protonation in ether, where it precipitates. An X-ray structure was not obtained for the Mo complex, but the analogous W derivative displays a pseudo-pentagonal bipyramidal structure. Since the two metal complexes show analogous NMR properties, the same structure is also assumed to be adopted by the Mo complex and is illustrated in Scheme 2. Both Mo and $\mathrm{W}$ cationic tetrahydride complexes are fluxional at room temperature, 
showing only one hydride resonance and one phosphorus resonance, but the $\mathrm{P}$ resonance decoalesces at low temperature, whereas the hydride resonance does not. The protonation of $\left[\mathrm{Cp} * \mathrm{Mo}(\mathrm{dppe}) \mathrm{H}_{3}\right]$ in $\mathrm{MeCN}$ or the dissolution of $\left[\mathrm{Cp}^{*} \mathrm{MoH}_{4}(\mathrm{dppe})\right]^{+}$in $\mathrm{MeCN}$ gives a variety of products resulting from the substitution of $\mathrm{H}_{2}$ with $\mathrm{MeCN}$. The tungsten compound is stable under these conditions. ${ }^{[8]}$

Preliminary studies of the hydrogen bonding and proton transfer to the $\mathrm{Cp} * \mathrm{M}(\mathrm{dppe}) \mathrm{H}_{3}$ $(\mathrm{M}=\mathrm{Mo}, \mathrm{W})$ compounds with weaker proton donors has been recently communicated. ${ }^{[10]}$ We present here a full report of our investigation on the Mo compound, whereas further details concerning the $\mathrm{W}$ system, including a comparison of the two metal complexes, will be reported in a forthcoming paper. ${ }^{[1]}$

\section{Results}

\section{Experimental Studies}

Two solvents - THF or $\mathrm{CH}_{2} \mathrm{Cl}_{2}$ - were used for spectroscopic studies. Their relatively high polarity ( $\varepsilon=7.3$ for THF and 8.9 for $\mathrm{CH}_{2} \mathrm{Cl}_{2}$ ) helps maintain the ionic proton transfer products in solution. However, THF has itself pronounced proton acceptor properties and competes with the hydride complex for hydrogen bonding the proton donor. Therefore, much higher proton donor concentrations are needed in order to observe similar spectral changes to those in $\mathrm{CH}_{2} \mathrm{Cl}_{2 \cdot}{ }^{[12]}$ Unfortunately, compound [Cp* $\left.\mathrm{Mo}(\mathrm{dppe}) \mathrm{H}_{3}\right]$ slowly decomposes at room temperature in dichloromethane, probably by attack of the solvent $\mathrm{C}$ atom by the hydride ligand. The stability of the trihydride complex in $\mathrm{CH}_{2} \mathrm{Cl}_{2}$ is greatly enhanced at low temperatures, no visible change occurring at $200 \mathrm{~K}$ for at least $3 \mathrm{~h}$. Thus IR and UV-vis studies were carried out either in THF or in $\mathrm{CH}_{2} \mathrm{Cl}_{2}$ at low temperatures, or in $\mathrm{CH}_{2} \mathrm{Cl}_{2}$ at 
higher temperatures within a short timescale relative to the decomposition reaction. The NMR studies were carried out at low temperatures in $\mathrm{CD}_{2} \mathrm{Cl}_{2}$. In all cases, the extent of decomposition was carefully monitored to insure the significance of the results. The proton donors used in this study were 2-monofluoroethanol (MFE), 2,2,2-trifluoroethanol (TFE), hexafluoroisopropanol (HFIP), perfluorotert-butanol, (PFTB), and p-nitrophenol (PNP).

\section{(a) Analysis of the ${ }_{\mathrm{VOH}}$ region in the IR spectra}

The interaction between $\left[\mathrm{Cp} * \mathrm{Mo}(\mathrm{dppe}) \mathrm{H}_{3}\right]$ and proton donors was first studied by IR in the $v_{\mathrm{OH}}$ range by using MFE and TFE in $\mathrm{CH}_{2} \mathrm{Cl}_{2}$. The observed decrease of the intensity (A) of the $v_{\mathrm{OH}(\mathrm{free})}$ band and the appearance of a low-frequency shifted broad $v_{\mathrm{OH}}$ band for the hydrogen-bonded $\mathrm{OH}$ group is unquestionable evidence for the formation of hydrogen bonds between the alcohol $\mathrm{OH}$ proton and the transition metal hydride complex, although it does not establish the nature of the hydrogen bonding site. The $\Delta v_{\mathrm{OH}}$ band shift $\left[\Delta v_{\mathrm{OH}}=v_{\mathrm{OH}}(\mathrm{free})-\right.$ $\left.v_{\mathrm{OH}(\mathrm{bonded})}\right]$ increased with the strength of the proton donors (see Figure 1 and Table 1).

<Figure 1 and Table 1>

The hydrogen bond enthalpies, $\Delta \mathrm{H}_{\mathrm{HB}}$, were obtained by two independent methods (see Table 1). The first one is based on the empirical correlation outlined in Equation 1, originally established for classical H-bonds and later extended to hydrogen-bonds to metal centers and to hydride ligands as proton acceptors. ${ }^{[4]}$ The Van't Hoff method uses the integrated IR intensities for the free alcohol absorption band in the presence or absence of the hydride complex as a function of temperature. It has the advantage of also yielding the reaction entropy. There is quite good agreement between the reaction enthalpies obtained from the two 
methods. It is to be noted that the computed values for the interaction with TFE (see later) are in good agreement with these experimental results.

\section{$<$ Equation 1>}

\section{(b) Analysis of the $v_{M H}$ region in the IR spectra.}

The IR analysis in the $v_{M H}$ stretching vibration range was carried out with the goal of learning about the nature of the preferred hydrogen bonding site. Previous studies on monohydride complexes have demonstrated that the interaction with a hydride ligand has the effect of shifting the M-H stretching vibration to lower frequencies, whereas the opposite effect is associated to an interaction with the metal site or other ligands. ${ }^{[4]}$ For polyhydride compounds, however, the situation may not be so simple, since each vibrational normal mode results from the combination of more $\mathrm{M}-\mathrm{H}$ bond stretching vibrations, each of which may be affected by hydrogen bonding in a different way. A previous combined experimental and theoretical study on the dihydride complex $\mathrm{Ru}\left(\mathrm{PP}_{3}\right) \mathrm{H}_{2}\left[\mathrm{PP}_{3}=\mathrm{P}\left(\mathrm{CH}_{2} \mathrm{CH}_{2} \mathrm{PPh}_{2}\right)_{3}\right]^{[12]}$ was simplified by the fact that the two $\mathrm{M}-\mathrm{H}$ bonds, being trans to ligands that exert a very different trans effect, do not mix extensively with each other, thus each of the two bands is composed of an essentially pure stretching vibration of a single $\mathrm{M}-\mathrm{H}$ bond. The study of hydrogen bonding implicating the $\mathrm{Cp}_{2} \mathrm{NbH}_{3}$ complex, ${ }^{[7 \mathrm{c}]}$ having $\mathrm{C}_{2 \mathrm{v}}$ symmetry and one $v_{\mathrm{MH}}$ vibrational band resulting from the overlap of $2 a_{1}+b_{1}$ vibrations, ${ }^{[13]}$ revealed the formation of dihydrogen bonded complexes leading to band splitting with a low frequency shift for the hydrogen bonded $v_{\mathrm{MH}}$ band. Although hydrogen bonding for other polyhydride compounds has been investigated, ${ }^{[3 b]}$ no detailed analysis of the normal modes and how these are affected by hydrogen bonding have been reported. We intend to carry out such an analysis here for the $\left[\mathrm{Cp}^{*} \mathrm{Mo}(\mathrm{dppe}) \mathrm{H}_{3}\right]$ complex, by a combination of experimental and computational methods. 
The trihydride complex displays wide $v_{M H}$ bands of complex shape with the maxima at $1772 \mathrm{~cm}^{-1}$ in $\mathrm{CH}_{2} \mathrm{Cl}_{2}$ and at $1785 \mathrm{~cm}^{-1}$ in THF. Deconvolution of the spectrum in $\mathrm{CH}_{2} \mathrm{Cl}_{2}$, after subtraction of overtones due to the phenyl groups, yields two overlapping bands at 1821 and $1772 \mathrm{~cm}^{-1}\left(\Delta v_{1 / 2}=57\right.$ and $54 \mathrm{~cm}^{-1}$, correspondingly), see Figure 2. A third, much weaker band is found at $1904 \mathrm{~cm}^{-1}\left(\Delta v_{1 / 2}=41 \mathrm{~cm}^{-1}\right)$. However, its parameters are less reliable because of the low intensity and superposition with one of the phenyl overtones. Therefore, it will not be used later for the comparison with the theoretical data on $v_{\mathrm{MH}}$ in hydrogen bonded complexes. The intensities of the $v_{\mathrm{MH}}$ bands increase as the temperature is decreased. The extinction coefficient of the strongest band increases from 49.0 to $60.31 \mathrm{~mol}^{-1} \mathrm{~cm}^{-1}$ upon cooling from 290 to $200 \mathrm{~K}$ in THF.

$<$ Figure 2>

Upon interacting the $\left[\mathrm{Cp} * \mathrm{Mo}(\mathrm{dppe}) \mathrm{H}_{3}\right]$ complex with $\mathrm{MFE}$ at $200 \mathrm{~K}$ in $\mathrm{CH}_{2} \mathrm{Cl}_{2}$ the $v_{\mathrm{MH}}$ band becomes wider and shifts to lower frequencies by ca. $5 \mathrm{~cm}^{-1}$. A band decomposition analysis carried out after the subtraction of both dppe and MFE spectra shows that the two major bands become wider and appear at different positions: 1822 and $1769 \mathrm{~cm}^{-1}\left(\Delta v_{1 / 2}=73\right.$ and $60 \mathrm{~cm}^{-1}, \Delta v=+1$ and $-3 \mathrm{~cm}^{-1}$, respectively). These changes can be attributed to the effect of hydrogen bonding on the $\mathrm{MoH}_{3}$ moiety. The experiments in THF, as expected, necessitated the use of the stronger proton donors at higher concentrations in order to observe similar changes. For instance, using just a 10 -fold excess of TFE, the only observed change was a small low frequency band shift an intensity decrease upon increasing the temperature, just like in the absence of alcohol, without a shape change. This change is reversible up to $270 \mathrm{~K}$, demonstrating that no proton transfer occurs with this alcohol in THF up to $270 \mathrm{~K}$ (cf. proton 
transfer in $\mathrm{CH}_{2} \mathrm{Cl}_{2}$ later). A deeper analysis of the $\mathrm{M}-\mathrm{H}$ stretching vibrations in the absence and presence of proton donors will be carried below in the light of the theoretical data.

\section{(c) NMR and IR studies of proton transfer}

As stated in the introduction, the molybdenum trihydride complex can be protonated by $\mathrm{HBF}_{4} \cdot \mathrm{Et}_{2} \mathrm{O}$ to give the tetrahydride complex $\left[\mathrm{Cp}^{*} \mathrm{Mo}(\mathrm{dppe}) \mathrm{H}_{4}\right]^{+} .{ }^{[8]}$ New ${ }^{1} \mathrm{H}$ NMR investigations carried out at low temperatures (200-250 K) in $\mathrm{CD}_{2} \mathrm{Cl}_{2}$ using either $\mathrm{HBF}_{4} \cdot \mathrm{Et}_{2} \mathrm{O}$ or TFE show a direct transformation, without the detection of any intermediate (notably nonclassical species). With the weaker proton donor TFE, an equilibrium between the starting $\left[\mathrm{Cp} * \mathrm{Mo}(\mathrm{dppe}) \mathrm{H}_{3}\right]$ complex and the protonated product is established and a large excess is needed to achieve a high degree of proton transfer.

As well established, free and hydrogen bonded complexes exchange rapidly on the NMR time scale, yielding only one resonance. Typically, the effect of hydrogen bonding on chemical shifts is small, especially in the case of polyhydrides where the effect is averaged over the various hydride ligands. The $\left[\mathrm{Cp} * \mathrm{Mo}(\mathrm{dppe}) \mathrm{H}_{4}\right]^{+}$complex on one side, and the rapidly equilibrating mixture of the free trihydride complex and the hydrogen bonded adduct $\left[\mathrm{Cp} * \mathrm{Mo}(\mathrm{dppe}) \mathrm{H}_{3} \cdots \mathrm{HOR}_{\mathrm{F}}\right]$ on the other side, give rise to triplet resonances at ca. $\delta-3.7\left(\mathrm{~J}_{\mathrm{HP}}=\right.$ 37.4 Hz) and -6.0 $\left(\mathrm{J}_{\mathrm{HP}}=48.0 \mathrm{~Hz}\right)$ in the ${ }^{1} \mathrm{H}$ NMR spectrum at low temperatures $(190-210 \mathrm{~K})$. The positions of these peaks changes significantly with the temperature, moving to ca. -3.5 and -5.7 at $300 \mathrm{~K}$. The chemical shift difference between these resonances decreases steadily from $2.32 \mathrm{ppm}$ at $200 \mathrm{~K}$ to $2.22 \mathrm{ppm}$ at $300 \mathrm{~K}$. On the other hand, both chemical shifts, at a given temperature, do not seem highly dependent on the nature of the proton donor (TFE, HFIP or $\mathrm{HBF}_{4}$ ), nor on its concentration. Furthermore, the $\mathrm{J}_{\mathrm{HP}}$ values remain practically unchanged over the entire temperature range. Therefore, the chemical shift changes are probably unrelated to variations in hydrogen bonding equilibria. The relative amounts of the 
two species is also afforded by a parallel monitoring of the ${ }^{31} \mathrm{P}\left\{{ }^{1} \mathrm{H}\right\}$ NMR spectrum (resonance at $-75.0 \mathrm{ppm}$ and $-92.8 \mathrm{ppm}$, respectively). As for the case of the ${ }^{1} \mathrm{H}$ NMR resonances, the ${ }^{31} \mathrm{P}\left\{{ }^{1} \mathrm{H}\right\}$ NMR chemical shifts do not depend on the nature and concentration of the proton donor.

The establishment of hydrogen bonding is more clearly evidenced from the change of longitudinal relaxation time $\left(\mathrm{T}_{1}\right)$ for the trihydride resonance, see Table 2. As expected, this parameter decreases upon addition of proton donors, proportionally with the strength of the donor. $^{[1 \mathrm{~b}, 4 \mathrm{~b}]}$ It is also of significance that the temperature corresponding to the $\mathrm{T}_{1 \mathrm{~min}}$ increases slightly upon protonation from 220 to $230 \mathrm{~K}$. This phenomenon signals a decreased correlation time $\left(\tau_{\mathrm{C}}\right)$, i.e. a slower tumbling motion, for the protonated species, in agreement with its expected larger size. Thus, slightly higher temperatures are needed to raise again $\tau_{\mathrm{C}}$ to the conditions required for the most efficient longitudinal relaxation $\left(\mathrm{w}_{0}{ }^{2} \tau_{\mathrm{C}}^{2} \approx 1\right)$. The $\mathrm{T}_{1 \text { min }}$ of the tetrahydride product is smaller relative to the parent complex, but not in the range expected for dihydrogen complexes. ${ }^{[14]}$ This decrease is expected since the dipolar relaxation implicates four hydride ligands instead of three. Note, however, that the tetrahydride resonance $T_{1}$ value is also sensitive, like that of the parent trihydride, to the nature of the proton donor used. A possible interpretation of this difference is a stronger hydrogen bonding between one or more hydride ligands with the stronger conjugate base $\mathrm{CF}_{3} \mathrm{CH}_{2} \mathrm{O}^{-}$, thereby increasing the average $\mathrm{H} \cdots \mathrm{H}$ distances.

<Table 2>

Complex $\left[\mathrm{Cp}^{*} \mathrm{Mo}(\mathrm{dppe}) \mathrm{H}_{4}\right]^{+}$was also characterized by means of IR spectroscopy (see Figure 3). After the addition of 1.1 equivalents of $\mathrm{HBF}_{4}$, new bands appeared in the spectrum at 1818,1839 and $1920 \mathrm{~cm}^{-1}$ (see spectrum b). Formation of bands at higher frequency upon 
protonation is spectroscopic evidence for the formation of a cationic classical product. Treating $\left[\mathrm{Cp} * \mathrm{Mo}(\mathrm{dppe}) \mathrm{H}_{3}\right]$ with 7 equivalents of HFIP in THF at $200 \mathrm{~K}$ did not lead to significant proton transfer, only a minor decrease of the initial $1785 \mathrm{~cm}^{-1}$ band being observed after the subtraction of the HFIP spectrum (see spectrum c).

\section{$<$ Figure 3>}

The protonation process was studied more extensively with a wider range of fluorinated alcohols of different strength in dichloromethane by variable temperature IR. An equilibrium between the hydrogen bonded system and the tetrahydride complex was observed, which shifts toward the protonation product for stronger alcohols and higher alcohol/Mo ratios. For PFTB, the complete disappearance of the trihydride occurs in the presence of a twofold excess at $200 \mathrm{~K}$. The addition of 2 equivalents of TFE leads to only $20 \%$ conversion, while a tenfold excess is required to consume nearly all the hydride precursor (see Figure 4). For the case of the weakest fluorinated alcohol MFE, a 50-fold excess lead only to a moderate decrease of the MoH band intensity. The proton transfer with TFE at variable temperatures has given kinetic information, see later. Above $250 \mathrm{~K}$, a slow evolution of the spectroscopic properties was observed, indicating instability for the tetrahydride product (see below). A quantitative measurement of the equilibrium position in a wide temperature range was not possible by IR spectroscopy because of the complex shape of the spectra, further complicated by the temperature dependence of the extinction coefficients. The thermodynamic parameters of this equilibrium were obtained from UV and NMR investigations as shown below.

$<$ Figure 4>

\section{(d) Establishment of the proton transfer stoichiometry}


The equilibrium resulting from the interaction between $\left[\mathrm{Cp}^{*} \mathrm{Mo}(\mathrm{dppe}) \mathrm{H}_{3}\right]$ and $p$-nitrophenol $\left(\mathrm{PNP} ; \mathrm{P}_{\mathrm{i}}=1.27\right)$ was investigated by $\mathrm{UV}$-visible spectroscopy. This was rendered possible by the sensitivity of the proton donor chromophore to hydrogen bonding and proton transfer, ${ }^{[15]}$ making it possible to probe the nature of the species in equilibrium. However, quantitative information on the concentration of each species was not accessible. Spectra were recorded for $\mathrm{CH}_{2} \mathrm{Cl}_{2}$ solutions of PNP $(0.001 \mathrm{M})$ in the presence of $\left[\mathrm{Cp} * \mathrm{Mo}(\mathrm{dppe}) \mathrm{H}_{3}\right]$ at different ratios from 1:0.1 to 1:2, in the $200-250 \mathrm{~K}$ temperature range, where the observed spectral changes were fully reversible. The spectra show wide overlapping bands of both the phenol in its various forms and the hydride complexes (both free and dihydrogen bonded). The absence of free phenolate is signaled by the absence of a band at $430 \mathrm{~nm}$. A deconvolution analysis yields three bands with maxima at 312, 351, and $395 \mathrm{~nm}$. The first two bands are assigned to free PNP and to the dihydrogen bonded complex $\left[\mathrm{Cp}^{*}(\mathrm{dppe}) \mathrm{MoH}_{3}\right] \cdots \mathrm{HOC}_{6} \mathrm{H}_{4} \mathrm{NO}_{2}$. Note that the $351 \mathrm{~nm}$ band is red shifted not only relative to free $\operatorname{PNP}(\Delta \lambda=39 \mathrm{~nm})$, but also to the related iron complex $[\mathrm{Cp} *($ dppe $) \mathrm{FeH}] \cdots \mathrm{HOC}_{6} \mathrm{H}_{4} \mathrm{NO}_{2}(340 \mathrm{~nm}, \Delta \lambda=11 \mathrm{~nm}),{ }^{[16]}$ signaling a stronger hydrogen bonding. This is consistent with the higher basicity factor of [Cp* $\left.\mathrm{Mo}(\mathrm{dppe}) \mathrm{H}_{3}\right]$ (Table 1), vs. that of $[\mathrm{Cp} * \mathrm{Fe}(\mathrm{dppe}) \mathrm{H}](1.35-1.38) .{ }^{[16]}$ The band at $395 \mathrm{~nm}$ is attributed to a hydrogenbonded phenolate ion, $\left[\mathrm{Cp} *(\mathrm{dppe}) \mathrm{MoH}_{4}\right]^{+} \ldots[\mathrm{OAr}]^{-}$, since this is blue-shifted from the free phenolate band by $35 \mathrm{~nm}$. Notably, this band is red shifted in comparison to the corresponding band previously attributed to $\left[\mathrm{Cp} *(\mathrm{dppe}) \mathrm{Fe}\left(\mathrm{H}_{2}\right)\right]^{+} \ldots[\mathrm{ArOHOAr}]^{-} \cdot{ }^{[6]}$ The assignment of this absorption to the 1:1 hydrogen-bonded ion pair, rather than to a species containing a homoconjugated pair [ArOHOAr] $]^{-}$, was confirmed by the titration experiment (see Figure 5). Therefore, the proton accepting strength of the $\mathrm{Cp}^{*}(\mathrm{dppe}) \mathrm{MoH}_{3}$ complex is sufficiently high to abstract a proton from a single molecule of PNP. 
$<$ Figure 5>

The stoichiometry was also probed with a weaker proton donor, i.e. HFIP $\left(\mathrm{P}_{\mathrm{i}}=1.05\right)$ by way of a kinetics approach, since HFIP and the species derived from its protonation do not contain chromophores allowing their direct detection. The reaction was studied in toluene at $293 \mathrm{~K}$ under pseudo-first order conditions with $\mathrm{HFIP} / \mathrm{MoH}_{3}$ ratios in the $20-80$ range, using the stopped-flow technique. The proton transfer step required a few seconds to reach equilibrium. On a much longer time scale, a slower decomposition reaction occurred as indicated by the NMR monitoring (see below). The time evolution of the spectra could be properly fitted on the basis of a first order decay, giving an observed rate constant that turned out to be independent of the alcohol concentration, see Figure 6 . The average value for $k_{\text {lobs }}$ is $10.1 \pm 0.2 \mathrm{~s}^{-1}$. This result is consistent with the involvement of a single HFIP molecule in the rate-determining step (Scheme 3), because the hydrogen bonding pre-equilibrium is heavily shifted to the adduct under these conditions, see Equation 2. Therefore, since $K_{\mathrm{HB}}[\mathrm{HA}]>>1$, the expression simplifies to $k_{\mathrm{obs}}=\left(k_{1}+k_{-1}\right)$. In the previously published kinetics study of the $[\mathrm{Cp} * \mathrm{Fe}(\mathrm{dppe}) \mathrm{H}]+\mathrm{HFIP}$ system, on the other hand, a first order dependence on [HFIP] was observed under the same $\left(K_{\mathrm{HB}}[\mathrm{HA}] \gg>1\right)$ conditions. This difference is again consistent with the higher proton accepting ability of $\left[\mathrm{Cp}^{*} \mathrm{Mo}(\mathrm{dppe}) \mathrm{H}_{3}\right]$ vs. $[\mathrm{Cp} * \mathrm{Fe}(\mathrm{dppe}) \mathrm{H}]$.

$<$ Figure 6 and Scheme 3>

$<$ Equation 2>

(e) Thermodynamics of the proton transfer equilibrium.

The equilibrium of proton transfer to $\left[\mathrm{Cp}^{*} \mathrm{Mo}(\mathrm{dppe}) \mathrm{H}_{3}\right]$ was investigated by UV-visible and ${ }^{31} \mathrm{P}$ NMR spectroscopies in the $200-240 \mathrm{~K}$ temperature range using TFE as proton 
donors. The results of the UV-visible study using TFE are shown in Figure 7. The spectra of the initial trihydride (a) and final tetrahydride (b) complexes have very different extinction coefficients at the $\lambda_{\max }$ of the trihydride species $(400 \mathrm{~nm}$ ): 2128 and 245 , respectively. The UV-visible properties of the dihydrogen-bonded complexes are essentially indistinguishable from those of the free hydride complex: the UV-vis spectra of $\left[\mathrm{Cp}^{*} \mathrm{Mo}(\mathrm{dppe}) \mathrm{H}_{3}\right](0.02 \mathrm{M})$ in the presence of 15 equiv. MFE do not differ significantly from those of pure trihydride. The same phenomenon was observed earlier for iron hydride. ${ }^{[6]}$ Upon addition of TFE at $200 \mathrm{~K}$, $54 \%$ of the complex converts to the tetrahydride, leading to an absorption decrease. The intensity of the band increases upon heating, showing that the equilibrium shifts towards the initial complex. These changes are perfectly reversible in the $200-240 \mathrm{~K}$ range.

\section{$<$ Figure 7>}

The temperature reversibility enabled the determination of the equilibrium constant for the formation of $\left[\mathrm{Cp} * \mathrm{Mo}(\mathrm{dppe}) \mathrm{H}_{4}\right]^{+} \mathrm{OCH}_{2} \mathrm{CF}_{3}{ }^{-}$. It was assumed that the equilibrium involves only one TFE molecule, as experimentally verified for the PNP and HFIP systems (see above, Scheme 3). Taking into account the above determined hydrogen bond formation constant $K_{\mathrm{HB}}$, the analysis of the data of Figure 7 led to the calculation of the proton transfer equilibrium constant $K_{\mathrm{PT}}$ at each temperature. A van't Hoff analysis of these $K_{\mathrm{PT}}$ constants yields $\Delta \mathrm{H}^{\circ}{ }_{\mathrm{PT}}=-2.8 \pm 0.4 \mathrm{kcal} \mathrm{mol}^{-1}$ and $\Delta \mathrm{S}^{\circ}{ }_{\mathrm{PT}}=-15 \pm 2 \mathrm{cal} \mathrm{mol}^{-1} \mathrm{~K}^{-1}$ for the proton transfer process.

The proton transfer equilibrium constants were also obtained by ${ }^{1} \mathrm{H}$ NMR spectroscopy. Like for the UV-visible investigation, the NMR technique only provides information on the sum of the concentrations of rapidly equilibrating free trihydride and its hydrogen bonded adduct. Knowledge of the $K_{\mathrm{HB}}$ allowed the calculation of the individual concentrations, from 
which the $K_{\text {PT }}$ constants could be calculated at each temperature. The van't Hoff analysis yields $\Delta \mathrm{H}^{\circ}{ }_{\mathrm{PT}}=-2.7 \pm 0.5 \mathrm{kcal} \mathrm{mol}^{-1}$ and $\Delta \mathrm{S}^{\circ}{ }_{\mathrm{PT}}=-11 \pm 2 \mathrm{cal} \mathrm{mol}^{-1} \mathrm{~K}^{-1}$. These values are identical to those established from the low-temperature UV-visible data within experimental error.

\section{(f) Decomposition of the proton transfer product: hydrogen evolution.}

NMR monitoring of the $\left[\mathrm{Cp} * \mathrm{Mo}(\mathrm{dppe}) \mathrm{H}_{3}\right]-\mathrm{TFE}$ interaction at high temperatures $(>280$ K) revealed further irreversible evolution. The hydride resonances of the starting trihydride and the protonated tetrahydride complexes disappeared completely within $2 \mathrm{~h}$ at room temperature. No new hydride resonance appeared in the spectrum. On the other hand, the formation of a new diamagnetic product was indicated by the replacement of the $\mathrm{Cp}^{*}$ resonances ( $\delta 1.69$ for the trihydride and 1.83 for the tetrahydride complexes) with a new one at $\delta 1.58$ in the ${ }^{1} \mathrm{H}$ NMR and by the appearance of a resonance at $\delta-69.5$ in the ${ }^{31} \mathrm{P}\left\{{ }^{1} \mathrm{H}\right\} \mathrm{NMR}$ spectrum. This indicates the selective formation of a single, hydride-free diamagnetic product. This evolution is accompanied by the appearance of a new sharp resonance at $\delta 4.61$ in the ${ }^{1} \mathrm{H}$ NMR spectrum, which is characteristic of free $\mathrm{H}_{2}$. All this evidence points to reductive elimination of two $\mathrm{H}_{2}$ molecules from the tetrahydride complex $\left[\mathrm{Cp}^{*} \mathrm{MoH}_{4}(\mathrm{dppe})\right]^{+}$, the product being stabilized by coordination of the trifluoroethoxide anion.

Stable 16-electron compounds of type $\left[\left(\mathrm{C}_{5} \mathrm{R}_{5}\right) \mathrm{MoL}_{2} \mathrm{X}\right]$, the $\mathrm{X}$ ligand has $\pi$-donating properties, have previously been reported, e.g. $\left[\mathrm{CpMo}(\mathrm{CO})_{2}\left(\mathrm{AsBu}_{2}{ }_{2}\right)\right]{ }^{[17]}$ $\left[\mathrm{Cp} * \mathrm{Mo}\left(\mathrm{PMe}_{3}\right)\left(\mathrm{PHPh}_{2}\right)\left(\mathrm{PPh}_{2}\right)\right],{ }^{[18]}[\mathrm{Cp} * \mathrm{Mo}(\mathrm{dppe}) \mathrm{Cl}]{ }^{[19]}$ and $\left[\mathrm{CpMo}\left(\mathrm{PMe}_{3}\right)_{2}(\mathrm{OH})\right] .^{[19-20]}$ These precedents suggest that the $\left[\mathrm{Cp} * \mathrm{Mo}(\mathrm{dppe})\left(\mathrm{OCH}_{2} \mathrm{CF}_{3}\right)\right]$ molecule may be stable. Interestingly, compounds $\left[\mathrm{CpMo}\left(\mathrm{PMe}_{3}\right)_{2}(\mathrm{OH})\right]$ and $\left[\mathrm{Cp}^{*} \mathrm{Mo}(\mathrm{dppe}) \mathrm{Cl}\right]$ have two unpaired electrons, whereas our observed $\mathrm{H}_{2}$ elimination product is diamagnetic like compound 
$\left[\mathrm{Cp} * \mathrm{Mo}\left(\mathrm{PMe}_{3}\right)\left(\mathrm{PHPh}_{2}\right)\left(\mathrm{PPh}_{2}\right)\right]{ }^{[18]}$ It is also possible, however, that one additional TFE molecule adds to the system to afford an 18-electron adduct, which could even be further stabilized by intramolecular hydrogen bonding, see Scheme 4.

\section{$<$ Scheme 4>}

The ${ }^{1} \mathrm{H}$ NMR spectrum does not remove this ambiguity, because only one $\delta_{\mathrm{CH} 2}$ resonance for TFE is observed, at the same position as in free TFE ( $\delta$ ca. 3.9). It is not split nor shifted by the deprotonation process, possibly because of a rapid exchange between the free alcohol and its conjugate anion. The absence of a new resonance for a coordinated TFE molecule represents only negative evidence, because fast exchange could also average the resonances of free $\mathrm{TFE} / \mathrm{CF}_{3} \mathrm{CH}_{2} \mathrm{O}^{-}$with that of any coordinated TFE. Neither does the $\mathrm{OH}$ resonance give any useful information, since it also remains unsplit under all conditions because of rapid exchange processes. In addition, the position of this resonance is highly temperature and concentration dependent, even before any dihydrogen evolution from $\left[\mathrm{Cp}^{*} \mathrm{MoH}_{4}(\mathrm{dppe})\right]^{+}$ takes place. All our attempts to isolate the final product in the crystalline state have failed. The spin states dichotomy for complex $\left[\mathrm{Cp} * \mathrm{Mo}(\mathrm{dppe})\left(\mathrm{OCH}_{2} \mathrm{CF}_{3}\right)\right]$, as well as the thermodynamics of further TFE coordination has been investigated by DFT calculations (vide infra).

\section{Computational studies}

The interaction of $\left[\mathrm{Cp} * \mathrm{Mo}(\mathrm{dppe}) \mathrm{H}_{3}\right]$ with fluorinated alcohols has been studied theoretically by using the model complex $\left[\mathrm{CpMo}(\mathrm{dpe}) \mathrm{H}_{3}\right]\left(\mathrm{dpe}=\mathrm{H}_{2} \mathrm{PCH}_{2} \mathrm{CH}_{2} \mathrm{PH}_{2}\right)$ and TFE and HFIP as proton donors, both in gas phase and in dichloromethane. Test calculations for 
the real complex have also been performed. The computational study was carried out with several objectives in mind: (i) explore the thermodynamics of hydrogen bonding at different sites; (ii) investigate the effect of hydrogen bonding at different sites on the vibrational modes of the $\mathrm{MoH}_{3}$ moiety; (iii) investigate the stability of the protonation products and the possible involvement of nonclassical intermediates during the proton transfer process; (iv) determine the protonation pathway; $(v)$ rationalize the further evolution of the protonation product.

\section{(a) The free trihydride complex.}

The optimization of the free $\left[\mathrm{CpMo}(\mathrm{dpe}) \mathrm{H}_{3}\right]$ model system gave a geometry that is in close correspondence with that observed experimentally ${ }^{[8-9]}$ for the full $\left[\mathrm{Cp}^{*} \mathrm{Mo}(\mathrm{dppe}) \mathrm{H}_{3}\right]$ system. For the purpose of the present discussion, the most important parameters are those related to the $\mathrm{MoH}_{3}$ moiety, see Figure 8 . Taking the plane that contains the two $\mathrm{P}$ atoms and the center of the $\mathrm{Cp}$ as a reference, the three $\mathrm{H}$ ligands are disposed asymmetrically, two (H1 and $\mathrm{H} 2$ ) on one side and one (H3) on the other side. The unique $\mathrm{H} 3$ atom shows the longest distance to the Mo center $(1.724 \AA$ ). The other two hydrides seem to occupy approximately symmetric positions relative to the Mo-H vector to the unique $\mathrm{H}$ ligand $\left(\mathrm{H} 3-\mathrm{Mo}-\mathrm{H} 1=132^{\circ}\right.$, $\mathrm{H} 3-\mathrm{Mo}-\mathrm{H} 2=129^{\circ}$ ), but they in fact show quite different Mo-H distances. One distance (to $\mathrm{H} 2)$ is similar to that of the unique hydride $(1.717 \AA)$, whereas the other one is much shorter (1.682 $\AA$ ). This asymmetry parallels a slight asymmetry in the Cp*Mo(dppe) moiety (the two CNT-Mo-P angles are different at 131.1 and $143.1^{\circ}$ ) and its origin is not clear. The three hydride ligands have quite different Mulliken charges: $-0.017,-0.003$ and -0.053 for $\mathrm{H} 1, \mathrm{H} 2$ and H3, respectively. Thus H3 is clearly the most hydridic site. The distance between $\mathrm{H} 1$ and

$\mathrm{H} 2(1.753 \AA)$ indicates that they do not directly interact with each other because it is longer than the longest separation between hydrogen atoms in what have been described as "stretched dihydrogen ligands" (e.g. $1.49 \AA$ in $\left.\left[\mathrm{OsH}_{5}\left(\mathrm{PMe}_{2} \mathrm{Ph}\right)_{3}\right]^{+}\right) .{ }^{[21]}$ In addition, a theoretical analysis 
of another stretched dihydrogen complex (i.e. $\left[\mathrm{Os}(\mathrm{H} \cdots \mathrm{H})\left(\mathrm{NH}_{2} \mathrm{CH}_{2} \mathrm{CH}_{2} \mathrm{NH}_{2}\right)_{2}\left(\mathrm{HCO}_{2}\right)\right]^{+}$with a distance of $1.428 \AA$ ) indicates no critical point connecting the two atoms. ${ }^{[22]}$

\section{$<$ Figure 8>}

The analysis of the M-H normal modes in the free complex, also represented in Figure 8, will serve as a basis for discussion of the changes induced by hydrogen bonding. A comparison between the experimental spectrum for compound $\left[\mathrm{Cp} * \mathrm{Mo}(\mathrm{dppe}) \mathrm{H}_{3}\right]$ and the computed one for the $\left[\mathrm{CpMo}(\mathrm{dpe}) \mathrm{H}_{3}\right]$ model shows a rather good agreement, both in terms of the frequencies and the relative intensities. As shown in Figure 8, the higher energy normal mode $\left(v_{1}\right)$ is essentially a pure stretching vibration of the hydride ligand H1, which shows the shortest (and therefore strongest) bond. The other two vibrations are relatively close to each other in frequency and are a mixture of the other two $\mathrm{M}-\mathrm{H}$ bond vibrations, the higher frequency one $\left(v_{2}\right)$ being an in-phase combination with the major contribution from the shorter bond to $\mathrm{H} 2$, and the lower frequency one $\left(v_{3}\right)$ being an out-of-phase combination with the major contribution from the longer bond to $\mathrm{H} 3$.

\section{(b) Hydrogen bonded adducts with TFE: structures and vibrational modes}

$\left[\mathrm{CpMo}(\mathrm{dpe}) \mathrm{H}_{3}\right]$ has four potential hydrogen bonding sites: the three hydrides and the metal (Scheme 5).

\section{$<$ Scheme 5>}

To account for all the possible hydrogen bonded minima we optimized the adduct between TFE and the $\left[\mathrm{CpMo}(\mathrm{dpe}) \mathrm{H}_{3}\right]$ starting from the different regions around the metal. In 
this way five stable hydrogen-bonded structures were obtained, as shown in Figure 9. Table 3 shows the relevant optimized geometrical parameters. The computed frequencies and the normal modes for the M-H stretching vibrations are depicted in Figure 10.

$<$ Table 3>

$<$ Figure 9 and Figure 10>

The adducts can be classified depending on the proton acceptor site. System $\mathbf{A}$ is the only one where TFE interacts with the unique hydride ligand H3. In systems B (B1-B3) the interaction occurs at one or both of the other two hydride ligands H1 and H2 that occupy pseudo-equivalent positions. Systems $\mathbf{B 2}$ and $\mathbf{B 3}$ are topologically related since they exhibit the same Mo-H $\cdots \mathrm{H}-\mathrm{O}$ moiety. They differ in the relative orientation of the proton donor molecule, which places the C-H bond in front of the second hydride in $\mathbf{B 3}$ and in the opposite direction in B2. In system B1 the alcohol molecule is placed with the same relative orientation as in $\mathbf{B 2}$ but farther from the $\mathrm{Cp}$ ring. Both in $\mathbf{B} 1$ and $\mathbf{B} 2$ the proton is closer to $\mathrm{H} 2$, but also interacting with H1. Thus, these geometries may be better described as containing a "bifurcated hydrogen bond", similar to that described for the $\mathrm{Cp}_{2} \mathrm{NbH}_{3} \cdot \mathrm{HOR}_{\mathrm{F}}$ adducts. ${ }^{[7 \mathrm{c}]} \mathrm{In}$ addition, the distance of the proton from the metal center in system $\mathbf{B} 1$ is also relatively short. In $\mathbf{B 3}$ the proton is interacting only with $\mathrm{H} 2$, with $\mathrm{H} 2 \cdot \bullet \cdot \mathrm{H}-\mathrm{O}$ and $\mathrm{Mo} \bullet \bullet \mathrm{H}-\mathrm{O}$ angles of $160.3^{\circ}$ and $170.4^{\circ}$, respectively. Finally, system $\mathbf{C}$ is the only one where the most important interaction appears to involve the metal center, as indicated by the shortest Mo $\cdots \mathrm{H}$ distance and the almost linear Mo $\cdots \mathrm{H}-\mathrm{O}$ bond. The metal-proton interaction is accompanied by a relatively long $\mathrm{H} \cdots \mathrm{H} 3$ interaction $(2.104 \AA$ ). This initial description of the hydrogen-bonded adducts, based on the structural data, will be reinforced by the analysis of the changes in the 
vibrational frequencies and atomic charges of the $\mathrm{MoH}_{3}$ moiety on going from the free complex to the TFE adduct.

The evolution of the Mulliken charges on the hydride atoms and on the Mo atom upon going from the free complex to the TFE adducts also provides useful information. The relevant charges are collected in Table 4. The $\mathrm{O}-\mathrm{H}$ bond is lengthened in all complexes, in comparison to free TFE $(0.965 \AA)$. The magnitude of this elongation is variable but is always rather large $(0.012-0.015 \AA)$. The positive charge of the proton increases by $0.027-0.047$ units. In system A TFE interacts only with the unique hydride ligand (H3). The negative charge of $\mathrm{H} 3$ increases from -0.053 to $-0.128(\Delta q=-0.075)$, whereas the charges of $\mathrm{H} 1$ and $\mathrm{H} 2$ remain essentially unchanged and that on Mo slightly decreases $(\Delta \mathrm{q}=+0.009)$. The Mo$\mathrm{H} 3$ bond is significantly elongated $\left(\Delta \mathrm{r}_{\mathrm{M}-\mathrm{H}}=+0.010 \AA\right)$, whereas the Mo-H1 and Mo-H2 bonds are less affected (slight contraction for the former and slight elongation for the latter). The composition of the three M-H vibrational modes (Figure 10) remains close to that observed in the free trihydride (Figure 8). The $v_{1}$ mode is blue-shifted by $+17 \mathrm{~cm}^{-1}$, in agreement with the slight contraction of the Mo-H1 bond, the $v_{2}$ mode does not shift significantly (the major contribution is from Mo-H2, which maintains essentially the same distance) and the $v_{3}$ mode is strongly red-shifted $\left(\Delta v_{3}=-21 \mathrm{~cm}^{-1}\right)$, correlating with the weakening of the Mo-H3 bond by the hydrogen bond.

$<$ Table 4>

The $\mathrm{H} 1$ and $\mathrm{H} 2$ hydrides are involved in the hydrogen bond in systems B1-B3. For system B3, the major observed effects of hydrogen bonding are a significant lengthening of the Mo-H2 bond (+0.019 $\AA$ ), a slight shortening of Mo-H3 (-0.007 $\AA$ ), a dramatic increase for 
the $\mathrm{H} 2$ negative charge $(-0.120)$ and a slight decrease for that of Mo $(+0.020)$. Therefore, these charge and bond distance changes confirm the description of this adduct as involving a dihydrogen bond to $\mathrm{H} 2$. The $v_{1}$ vibration is very little influenced by the dihydrogen bonding $\left(\Delta v_{1}=+4 \mathrm{~cm}^{-1}\right)$, whereas $v_{2}$ and $v_{3}$ are dramatically affected (Figure 10). In fact, hydrogen bonding with $\mathrm{H} 2$ weakens the Mo-H2 bond to such a point that the $v_{2}$ mode (to which the Mo$\mathrm{H} 2$ vibration contributes the most) now appears at lower frequency than $v_{3}\left(\Delta v_{2}=-36 \mathrm{~cm}^{-1}\right)$. Conversely, $v_{3}$ is shifted to higher frequency $\left(\Delta v_{3}=+17 \mathrm{~cm}^{-1}\right)$, in agreement with the Mo-H3 bond shortening, and the band intensity is decreased by a factor of two. An additional contribution to the red-shift of $v_{2}$ and to the blue-shift of $v_{3}$ may be associated with the modified mixing: in-phase for $v_{2}$ and out-of-phase for $v_{3}$, i.e. opposite with respect to the situation in the free trihydride.

For system B2, the negative charge increases significantly, relative to the free trihydride complex, on both $\mathrm{H} 1(\Delta \mathrm{q}=-0.029)$ and especially $\mathrm{H} 2(\Delta \mathrm{q}=-0.085)$, correlating well with the $\mathrm{H} \bullet \bullet H$ distances (longer for $\mathrm{H} 1,1.944 \AA$; shorter for $\mathrm{H} 2,1.799 \AA$ ). The charge slightly decreases on Mo $(\Delta \mathrm{q}=+0.006)$. The trends of the $\mathrm{H} \bullet \bullet \mathrm{H}$ distances and hydride charges agree with the evolution of the Mo-H bond lengths: both Mo-H1 and Mo-H2 are lengthened (by +0.002 and $+0.008 \AA$, respectively), whereas Mo-H3 is shortened $(-0.004 \AA)$ (Table 3). The $\mathrm{O}-\mathrm{H}$ vector bisects the $\mathrm{H} 1 \mathrm{MoH} 2$ angle, with an essentially coplanar $\mathrm{MoH} 1 \mathrm{H} 2 \cdot \bullet \mathrm{HO}$ fragment. System B2, therefore, appears to be best described as having a bifurcated hydrogen bond with $\mathrm{H} 1$ and $\mathrm{H} 2$. This situation reflects onto the vibrational modes as follows. The $v_{1}$ mode appears at slightly higher frequency $\left(+3 \mathrm{~cm}^{-1}\right)$, which is unexpected because the Mo-H1 bond is slightly lengthened by the hydrogen bond. The $v_{2}$ mode exhibits a moderate low-frequency shift $\left(-16 \mathrm{~cm}^{-1}\right.$; a compromise between the Mo-H2 bond weakening 
and the Mo-H3 bond strengthening), whereas the $v_{3}$ mode correspondingly shows a moderate high-frequency shift $\left(+3 \mathrm{~cm}^{-1}\right)$ for the same reasons.

For system B1, on the other hand, the charge on H1 remains unchanged, whereas it increases significantly on $\mathrm{H} 2(-0.073)$ and also on the Mo atom (-0.051), suggesting that the metal center also participates directly to the hydrogen bonding. The $\mathrm{O}-\mathrm{H} \bullet \bullet$ Mo distance is 0.1 $\AA$ shorter in B1 than in B2. A folding of the $\mathrm{O}-\mathrm{H}$ vector along the $\mathrm{H} 1 \mathrm{H} 2$ axis by $141.2^{\circ}$ toward the metal, in the opposite direction from the $\mathrm{Cp}$ ring, signals an interaction that forces the proton donor to approach the metal center. These changes suggest the description of adduct B1 as featuring a bifurcated hydrogen bond to $\mathrm{H} 2$ and Mo. Note that, whereas the $\mathrm{H} \cdot \bullet \cdot \mathrm{H}$ distances would suggest that hydrogen bonding with $\mathrm{H} 2$ is stronger in B1 than in B2 (1.779 $\AA$ vs. $1.799 \AA$ ), the Mo-H2 distance shortens (-0.004 $\AA$ ), rather then lengthening, in B1. In addition, the charge on $\mathrm{H} 2$ increases to a smaller extent in B1 than in B2. These perturbations may be caused by the Mo $\bullet \cdot \mathrm{HO}$ interaction and suggest that conclusions about the hydrogen bond nature in a complicated polyatomic system should not be based solely on the $\mathrm{H} \bullet \bullet \mathrm{H}$ distances. The low-frequency shift for $v_{1}\left(-12 \mathrm{~cm}^{-1}\right)$ correlates with the lengthening of the Mo-H1 bond and the strong high-frequency shift for $v_{2}\left(+23 \mathrm{~cm}^{-1}\right)$ correlates with the Mo-H2 bond compression, whereas there is no clear correlation with the $\mathrm{H} \bullet \bullet \mathrm{H}$ distances. Note that system B1 exhibits mixing of the Mo-H1 and Mo-H2 vibrations in $v_{1}$ and $v_{2}$, whereas $v_{3}$ is an essentially pure Mo-H3 vibration. The latter experiences no shift relative to the free trihydride compound, consistent with the invariance of the Mo-H3 bond distance.

Finally, system $\mathbf{C}$ shows a dramatic increase of the metal negative charge $(\Delta \mathrm{q}=$ -0.106), whereas the charge on H3 increases only slightly $(\Delta q=-0.019)$. Together with the structural features discussed above, these charge variations suggest that the bonding in this adduct is dominated by the metal site, and is unique amongst all the optimized adducts A-C in 
this respect. It is interesting to observe that not only the Mo-H3 bond is elongated in this adduct $(+0.007)$, but so is also the Mo-H2 bond $(+0.008 \AA)$, whereas the Mo-H1 bond is slightly shortened. This phenomenon does not find an obvious explanation. The evolution of the normal modes is again in line with the observed changes of Mo- $\mathrm{H}$ bond lengths: $v_{1}$ shows a small high-frequency shift $\left(+4 \mathrm{~cm}^{-1}\right)$, whereas $v_{2}$ and $v_{3}$ exhibit large low-frequency shifts (-33 and $-20 \mathrm{~cm}^{-1}$, respectively).

\section{(c) Hydrogen bonded adducts with TFE: relative stability}

The relative stability of these systems was estimated by different ways, see Table 5 . Comparing the energy changes associated to the hydrogen bond formation, the stronger interactions are those involving the two equivalent hydride ligands. Structures $\mathbf{B}$ show the most exothermic hydrogen bond. This behavior can be traced back to the establishment of two dihydrogen bonds in $\mathbf{B 1}$ and $\mathbf{B 2}$ or only one but strong dihydrogen bond in $\mathbf{B 3} .^{[7 \mathrm{c}]}$ Although the primary interaction is shorter in system B3, the relative stability of the three systems is not too different. A fast exchange of the $\mathrm{ROH}$ molecule between the three $\mathbf{B}$ sites can be expected from the structural features and low energy differences found between the three isomers. The interactions at the unique hydride site (A) and at the metal site (C) have similar energies, around $2 \mathrm{kcal} \mathrm{mol}^{-1}$ less exothermic than for the $\mathbf{B}$ structures. A fast exchange between the $\mathbf{A}$ and $\mathbf{C}$ sites can be also expected. The gas phase complexation energies span a range between 9 and $12 \mathrm{kcal} \mathrm{mol}^{-1}$, similar to those calculated for the same kind of interactions in other transition metal hydride systems, ${ }^{[6,7 b, 7 c]}$ and notably higher than the experimental enthalpies. Previous results concerning hydrogen bonding in transition metal systems showed that the Basis Set Superposition Error (BSSE) can be very important in this type of systems. ${ }^{[7 c]}$ BSSEcorrected bonding energies have been calculated, showing that the basis set superposition error accounts for $40-50 \%$ of the interaction energy. However, after correction all the adducts 
are still stable, with interaction energies between 5 and $8 \mathrm{kcal} \mathrm{mol}^{-1}$. It is worth mentioning that a negative and significant interaction energy remains at the metal site after the BSSE correction, in contrast with what we have found in a recent study of the hydrogen bonding to the $[\mathrm{Cp} * \mathrm{Fe}(\mathrm{dppe}) \mathrm{H}]{ }^{[6]}$ This result demonstrates the basicity of the molybdenum center in this compound and points towards a competition between the hydride and the metal sites for the proton.

The calculated enthalpies, taking the BSSE-corrected energies, are slightly decreased, but the ordering $\mathbf{B}>\mathbf{C}>\mathbf{A}$ is preserved. The interaction enthalpy was also estimated on the basis of Iogansen's empirical relationships (Equation $1^{[23]}$ and Equation $3^{[24]}$ ) using the computed $v(\mathrm{OH})$ stretching vibration frequencies or $v(\mathrm{OH})$ band intensities $A$ that are also reported in Table 5. Remarkably, the $\Delta H$ computed in the different ways are very similar. Indeed, the highest values obtained (about $6 \mathrm{kcal} \cdot \mathrm{mol}^{-1}$ ) are close to the experimental hydrogen bond enthalpies. The $v(\mathrm{OH})$ bands are found at lower frequency $(\Delta v(\mathrm{OH})=227-$ $292 \mathrm{~cm}^{-1}$ ), and with a dramatically increased intensity (from $0.38 \cdot 10^{4} 1 \mathrm{~mol}^{-1} \mathrm{~cm}^{-2}$ in free TFE to (4.99-7.77) $10^{4} 1 \mathrm{~mol}^{-1} \mathrm{~cm}^{-2}$ in the $\mathrm{H}$-bonded adducts), in good agreement with the experimental observations. Both correlations work well for medium strength hydrogen bonds of organic bases and appear to be successfully applicable also to organometallic complexes. ${ }^{[4]}$ Note that Equation 3 is considered as universal (valid for different types of H-complexes in solution or in the gas phase) and more precise.

$<$ Table 5 and Equation 3>

PCM calculations give the solvation free energy of a species, and its partition into enthalpic and entropic parts is not possible. ${ }^{[25]}$ From the $\Delta \mathrm{G}_{\text {solv }}$ of free $\left[\mathrm{CpMo}(\mathrm{dpe}) \mathrm{H}_{3}\right]$, free TFE, and their adduct, it is possible to get a rough estimation of the $\Delta \mathrm{G}$ of the hydrogen bond 
formation in solution, which does not take into account the internal contributions to the entropy. The $\Delta \mathrm{G}$ obtained in this way for adducts $\mathbf{A}-\mathbf{C}$ in $\mathrm{CH}_{2} \mathrm{Cl}_{2}$ are collected in Table 5 . Although the $\Delta \mathrm{G}\left(\mathrm{CH}_{2} \mathrm{Cl}_{2}\right)$ are less exothermic than the $\Delta \mathrm{H}$ in gas phase, for all the adducts $\Delta \mathrm{G}\left(\mathrm{CH}_{2} \mathrm{Cl}_{2}\right)$ is negative, pointing out to the stability of the hydrogen bonded species in solution. Moreover the ordering $\mathbf{B}>\mathbf{C}>\mathbf{A}$ is maintained.

\section{(d) Protonation products}

The calculations on the protonation product, the system having the $\left[\mathrm{CpMo}(\mathrm{dpe}) \mathrm{H}_{4}\right]^{+}$ stoichiometry, reveal the existence of two stable local minima for the classical tetrahydride complex and another two for a dihydrogen-dihydride tautomer, $\left[\mathrm{CpMo}(\mathrm{dpe})\left(\mathrm{H}_{2}\right) \mathrm{H}_{2}\right]^{+}$. They can be envisaged as the products of the proton transfer to the different proton acceptor sites revealed by the hydrogen bonded adducts. The optimized structures are shown in Figure 11. Relevant geometrical parameters are available as Supporting Information.

$<$ Figure 11>

The most stable isomer is the tetrahydride TETRA1. This structure presents a rather symmetrical arrangement, with two hydrides at each side of the plane defined by the two phosphorus atoms and the center of the $\mathrm{Cp}$ ring. The tetrahydride nature of this complex is evident from the $\mathrm{H} \cdots \mathrm{H}$ distances, the shortest one being $1.799 \AA$ A. There are two sets of Mo-H distances, longer (1.708 and $1.706 \AA$ ) for the two most distant hydrides, and shorter $(1.671$ and $1.674 \AA$ ) for the closest ones. The geometry of TETRA1 agrees with the experimental structure of $\left[\mathrm{Cp}^{*} \mathrm{WH}_{4}(\mathrm{dppe})\right]^{+}$and its description as a distorted pseudo-pentagonal bipyramid (see Scheme 2). ${ }^{[8]}$ The four $\mathrm{H}$ ligands are practically in the same plane (the fourth $\mathrm{H}$ is only $0.010 \AA$ away) and one $\mathrm{P}$ atom is only $0.035 \AA$ away from the least-squares $\mathrm{H}_{4}$ plane. The five 
angles between adjacent bonds in the pseudo pentagonal plane are relatively similar and close to that expected for the equatorial ligands in a pentagonal bipyramid $\left(72^{\circ}\right)$. TETRA1 can be considered the product of proton transfer to the metal site, although it may also result from the oxidative addition of a coordinated dihydrogen ligand. Both possibilities will be considered in sections (e) and (f).

The second tetrahydride minimum, TETRA2, has three hydrides on one side of the P$\mathrm{C} \mathrm{p}_{\text {centroid }} \mathrm{P}$ plane and one on the opposite side. The Mo-H distances for the three hydrides on the same side are $1.666,1.710$ and $1.668 \AA$, the longest one being that to the central hydride. The shortest $\mathrm{H} \cdots \mathrm{H}$ distance is $1.602 \AA(\mathrm{H} 1 \cdots \mathrm{H} 2)$, in agreement with the tetrahydride nature of this isomer. The Mo-H distance of the unique hydride H3 is $1.691 \AA$. TETRA2 could be regarded as the protonation product at the metal site close to the hydrides $\mathrm{H} 1$ and $\mathrm{H} 2$. TETRA2 is considerably less stable than TETRA1, lying $8.0 \mathrm{kcal} \cdot \mathrm{mol}^{-1}$ higher.

Two dihydrogen-dihydride structures have been characterized as local minima (DIH1 and DIH2). Their geometries are comparable to that of the parent complex $\left[\mathrm{CpMo}(\mathrm{dpe}) \mathrm{H}_{3}\right]$, but with a $\eta^{2}-\mathrm{H}_{2}$ ligand in place of a hydride. DIH1 is the most stable dihydrogen-dihydride isomer, only $3.7 \mathrm{kcal} \cdot \mathrm{mol}^{-1}$ above TETRA1. The presence of a dihydrogen ligand in the coordination sphere of the metal is apparent from the H-H distance of $0.896 \AA$ between the adjacent $\mathrm{H} 3$ and $\mathrm{H} 4$ atoms. This structure is reached by protonation of the unique hydride $\mathrm{H} 3$ in the initial trihydride. The second dihydrogen-dihydride isomer (DIH2) is attained by proton transfer to the $\mathrm{H} 1$ or $\mathrm{H} 2$ ligands. The $\mathrm{H}-\mathrm{H}$ distance in the dihydrogen ligand $(0.851 \AA)$ is shorter than in DIH1, indicating a weaker metal- $\mathrm{H}_{2}$ interaction. In agreement with this, DIH2 is less stable than DIH1, at $5.1 \mathrm{kcal} \cdot \mathrm{mol}^{-1}$ above TETRA1.

We have also considered the relative stability of the four $\left[\mathrm{CpMo}(\mathrm{dpe}) \mathrm{H}_{4}\right]^{+}$isomers in dichloromethane. There is little change on going from the gas phase to the $\mathrm{CH}_{2} \mathrm{Cl}_{2}$ medium. 
The tetrahydride TETRA1 remains the most stable species in $\mathrm{CH}_{2} \mathrm{Cl}_{2}$, with TETRA2, DIH1 and DIH2 being placed 6.6, 3.3 and $5.0 \mathrm{kcal} \cdot \mathrm{mol}^{-1}$ above TETRA1.

To assess how the chosen model affects the results, we have studied the protonation products in the full system, performing full $\mathrm{QM}$ calculations on the actual $\left[\mathrm{Cp} * \mathrm{Mo}(\mathrm{dppe}) \mathrm{H}_{4}\right]^{+}$ complex. The four stable structures found for the model $\left[\mathrm{CpMo}(\mathrm{dpe}) \mathrm{H}_{4}\right]^{+}$system have also been located in the full system, with very similar arrangements of the $\mathrm{MoH}_{4}$ unit to the model systems. A general view of the optimized geometries is shown in the Supporting Information. As can be appreciated in Table S1, the structural changes induced by the modeling of the real ligands are minor.

The relative energies of the different isomers of the full system are comparable to those of the model system. The tetrahydride TETRA1 is still the most stable species, with TETRA2, DIH1 and DIH2 placed 7.0, 4.4 and $6.6 \mathrm{kcal} \cdot \mathrm{mol}^{-1}$ above TETRA1. Thus, the calculations indicate that the classical tetrahydride product TETRA1 is strongly favored relative to all possible dihydrogen structures. This result agrees with the experiment since the tetrahydride is the only observed protonation product. The presence of dihydrogen-dihydride species at low relative energies suggests that they may be intermediates along the proton transfer pathway.

The simplifications introduced in the modeling of the system have a very little influence in the relative energies of the protonation products. To further check the differences between the model and the full systems we have computed the gas phase proton affinity (PA), that is the energy change associated to Equation 4.

$<$ Equation 4> 
where [Mo] stands for $\mathrm{CpMo(dpe)} \mathrm{or} \mathrm{Cp} * \mathrm{Mo}(\mathrm{dppe})$ and TETRA1 has been considered the protonation product. The model system presents a slightly lower proton affinity (249.9 $\left.\mathrm{kcal} \cdot \mathrm{mol}^{-1}\right)$ than the full system $\left(271.0 \mathrm{kcal} \cdot \mathrm{mol}^{-1}\right)$, but the difference amounts to only $8 \%$. As all four protonated structures have very similar relative energies in the full and model systems, we can conclude that all the proton acceptor sites of the $\mathrm{MoH}_{3}$ unit are a bit more basic in the full system than in the model one.

\section{(e) Proton transfer reaction profiles with HFIP}

We have also carried out a study of the $\left[\mathrm{CpMoH}_{3}(\mathrm{dpe}) \cdot \mathrm{HFIP}\right]$ adduct, analogous to that illustrated above for the $\left[\mathrm{CpMoH}_{3}(\mathrm{dpe}) \cdot \mathrm{TFE}\right]$ adduct. The results are not detailed for the sake of brevity, but the main outcome is that five hydrogen bonded structures comparable to the A-C ones reported for TFE (Figure 9) have been located, which will be correspondingly labeled A', B1', B2', B3' and C'. They follow the same stability ordering $\mathbf{B}^{\prime}>\mathbf{C}^{\prime}>\mathbf{A}^{\prime}$, with slightly increased interaction energies, caused by the stronger acidity of HFIP compared with TFE. For instance, the $\Delta \mathrm{H}(\mathrm{BSSE})$ are $-3.9,-6.3,-5.7 .-6.8$ and $-4.4 \mathrm{kcal} \mathrm{mol}^{-1}$ for the HFIP adducts A', B1', B2', B3' and C', respectively.

When one imagines the reaction trajectory leading to proton transfer, it can be predicted that system C' may lead to the classical tetrahydride complex directly, whereas systems A'-B' could yield dihydrogen intermediates. The most stable protonation product (TETRA1) formally arises from proton transfer to C', whereas the most stable dihydrogen complex (DIH1) may be viewed as formally arising from proton transfer from $\mathbf{A}^{\prime}$ to the $\mathrm{H} 3$ hydride site. For this reason we have studied both proton transfer pathways. In addition, the close vicinity of the protonation sites in the $\mathbf{A}^{\prime}$ and $\mathbf{C}^{\prime}$ structures will allow a study of the direct competition for the proton between a hydride and the metal sites and a discussion of whether a direct proton transfer to the metal is possible in this case. 
Starting from the hydrogen bonded adducts $\mathbf{C}^{\prime}$ and $\mathbf{A}^{\prime}$, the final products of the proton transfer should be the ion pairs made up by the TETRA1 (metal site protonation) or DIH1 (hydride site protonation) cations and the $\left[\left(\mathrm{CF}_{3}\right)_{2} \mathrm{HCO}^{-}\left([\mathbf{X}]^{-}\right)\right.$anion. However, whereas the optimization of the TETRA1 $\cdot[\mathbf{X}]$ ion pair was successful, attempts to optimize the DIH1 $[\mathbf{X}]$ ion pair failed. Several optimizations starting from different input geometries were tried but led systematically to the same initial hydrogen bonded adduct. The optimized geometries of hydrogen bonded complexes and the ion pair are available in the Supporting Information.

As no stable dihydrogen-conjugate base ion pair was found, we have not pursued the proton transfer pathway at the hydride site. We have further explored the protonation at the metal. Initially the gas phase reaction profile leading from $\mathbf{C}^{\prime}$ to TETRA1 $[\mathbf{X}]$ has been investigated by using the $\mathrm{O}-\mathrm{H}$ distance of the HFIP donor as the pivot parameter along the reaction coordinate, all other geometrical parameters being optimized. Then, the maximum of this curve has been used as starting point to locate the transition state, which practically coincides with this maximum. The profile in the dichloromethane solvent was obtained from single-point calculations on each point of the gas phase profile with the solvent PCM. The energy of the starting hydrogen-bonded adduct $\mathbf{C}$ ' was taken as the zero of energy. The energetic profiles are depicted in Figure 12.

$<$ Figure 12>

The gas-phase energy barrier to form the ion pair at the metal site is $24.7 \mathrm{kcal} \mathrm{mol}^{-1}$. The $\mathrm{CH}_{2} \mathrm{Cl}_{2}$ solvent slightly favors the kinetics of the proton transfer, decreasing the energy barrier to $22.8 \mathrm{kcal} \mathrm{mol}^{-1}$. In the transition state the $\mathrm{O}-\mathrm{H}$ bond is completely broken $(\mathrm{O}-\mathrm{H}=$ $1.581 \AA$ ) and the Mo-H bond is almost formed $(\mathrm{Mo}-\mathrm{H}=1.795 \AA)$. The distance between the proton that is being transferred and the contiguous $\mathrm{H} 3$ hydride $(1.795 \AA)$ is too long to 
consider the formation of a dihydrogen ligand. Thus, even in this crowded system there is a pathway for protonating the metal, without involvement of the hydride ligands.

There is experimental evidence that the participation of a second molecule of the proton donor might be crucial for the proton transfer to transition metal hydride by means of the so-called homoconjugate pairing effect. ${ }^{[2 f, 7 a, 16]}$ In our previous theoretical studies, the second proton donor molecule was used to locate the gas phase minima of the protonated species. $^{[6,7 b, 7 c]}$ Thus, we have also studied the proton transfer to complex $\left[\mathrm{CpMo}(\mathrm{dpe}) \mathrm{H}_{3}\right]$ with two HFIP molecules. ${ }^{[6,16]}$ The final products of the proton transfer are the ion pairs made up by the TETRA1 or DIH1 cations and the $\left[\left(\mathrm{CF}_{3}\right)_{2} \mathrm{HCO} \cdots \mathrm{HOCH}\left(\mathrm{CF}_{3}\right)_{2}\right]^{-}\left(\left[\mathbf{X H X}^{-}\right)\right.$ homoconjugate anion. With the inclusion of the second $\mathrm{AH}$ molecule, both ion pairs give stable local minima and it is possible to study the proton transfer process both at the metal and hydride sites. The corresponding starting points are the hydrogen bonded adducts $\mathbf{C} \cdot$.HFIP and $\mathbf{A} \cdot \mathbf{H F I P}$, with a second HFIP molecule joined by a $\mathrm{O} \cdots \mathrm{H}$ hydrogen bond to the first HFIP molecule. The optimized geometries are available in the Supporting In formation.

The thermodynamic viability of the proton transfer involving a second alcohol molecule (Equation 5) is very different from the situation shown above for a single HFIP molecule. Now the reaction is clearly exothermic, by $-5.2 \mathrm{kcal}^{\mathrm{mol}^{-1}}$ for the C+HFIP/TETRA1 $\cdot[\mathbf{X H X}]$ couple and $-6.2 \mathrm{kcal} \mathrm{mol}^{-1}$ for the A+HFIP/DIH1 $[\mathbf{X H X}]$ one. $\Delta \mathrm{G}\left(\mathrm{CH}_{2} \mathrm{Cl}_{2}\right)$ values, although considerably decreased $\left(-1.6\right.$ and $-0.7 \mathrm{kcal} \mathrm{mol}^{-1}$ for TETRA1 and DIH1, respectively), suggest the thermodynamic feasibility of the reaction in dichloromethane and indicate that the equilibrium is displaced toward the right. The presence of a strong hydrogen bond in the homoconjugated pair has a substantial impact on the overall reaction energy. 
$<$ Equation 5>

Both reaction profiles, leading from $\mathbf{A}^{\prime} \cdot \mathbf{H F I P}$ to $\mathbf{D I H 1} \cdot[\mathbf{X H X}]$ and from $\mathbf{C} \cdot \mathbf{H F I P}$ to TETRA1 $\cdot[\mathbf{X H X}]$ have been investigated, both in the the gas phase and in dichloromethane solvent, taking the $\mathrm{O}-\mathrm{H}$ distance of the transferring proton as the reaction coordinate. The energy of the starting hydrogen-bonded adduct was taken as the zero of energy in each case. The energetic profiles are depicted in Figure 13.

$<$ Figure 13>

The gas-phase barriers to form the ion pair at the hydride and the metal site are 11.2 and $12.9 \mathrm{kcal} \mathrm{mol}{ }^{-1}$, respectively. As already found with one HFIP molecule, the $\mathrm{CH}_{2} \mathrm{Cl}_{2}$ solvent favors the kinetics of the proton transfer, decreasing the energy barriers to 9.4 and $10.2 \mathrm{kcal} \mathrm{mol}^{-1}$, respectively. The ion pairs resulting from the protonation at the hydride $\left([\mathbf{D I H 1}]^{+} \cdot[\mathbf{X H X}]^{-}\right)$and metal site $\left.(\text {TETRA1 }]^{+} \cdot[\mathbf{X H X}]^{-}\right)$are found to be 6.3 and $4.8 \mathrm{kcal} \mathrm{mol}^{-}$ ${ }^{1}$, respectively, above the hydrogen-bonded complexes in the gas phase, and 2.7 above and 0.3 kcal mol ${ }^{-1}$ below, in dichloromethane. The solvent also favors the thermodynamics of the proton transfer, stabilizing the charged species to a greater extent than the initial neutral hydrogen-bonded ones. The role played by the homoconjugate pairing in the proton transfer process can be appreciated following the evolution of the two O-H distances of the HFIP dimer throughout the protonation process. In the hydrogen bonded initial species $\mathbf{A}^{\prime} \cdot \mathbf{H F I P}$ and C'.HFIP there is a normal hydrogen bond between the oxygen atom of the first HFIP molecule and the proton of the second one. The $\mathrm{O} \cdots \mathrm{O}$ and $\mathrm{O} \cdots \mathrm{H}$ distances are 2.718 and $1.761 \AA$ in A'·HFIP and 2.703 and $1.745 \AA$ in $\mathbf{C}^{\prime} \cdot$ HFIP. The O-H bond of the second HFIP molecule is only slightly lengthened by the hydrogen bond interaction $(\mathrm{O}-\mathrm{H}=0.980$ and 0.981 
$\AA$ in $\mathbf{A} \cdot$ HFIP and $\mathbf{C}^{\prime} \cdot \mathbf{H F I P}$, respectively; the O-H distance in free HFIP is $0.968 \AA$ ). The presence of a strong $[\mathrm{A} \cdots \mathrm{H} \cdots \mathrm{A}]^{-}$hydrogen bond in the anion of the ion pair can be inferred from the shortening of the $\mathrm{O} \cdots \mathrm{O}$ distance $\left(2.439\right.$ and $2.396 \AA$ in $[\mathbf{D I H 1}]^{+} \cdot[\mathbf{X H X}]^{-}$and $[\text { TETRA1 }]^{+} \cdot[\mathbf{X H X}]^{-}$, respectively). The $\mathrm{O} \cdot \cdot \mathrm{H}$ distances $(1.359$ and $1.241 \AA)$ and $\mathrm{O}-\mathrm{H}-\mathrm{O}$ angles $\left(178.5\right.$ and $\left.178.1^{\circ}\right)$ also agree with a proton shared by two $[\mathbf{X}]^{-}$units. The acidity of the coordinated dihydrogen makes the homoconjugate anion interact more strongly with the $\mathrm{H}$ of the dihydrogen than with that of the tetrahydride (M-H...O distances of 2.467 and $2.493 \AA$ in $[\text { DIH1 }]^{+} \cdot[\mathbf{X H X}]^{-}$and $[\text {TETRA1 }]^{+} \cdot[\mathbf{X H X}]^{-}$, respectively). In opposition, the $\mathrm{O} \cdots \mathrm{H} \cdots \mathrm{O}$ interaction in the homoconjugate anion is stronger in $[\text { TETRA1] }]^{+} \ldots[\mathbf{X H X}]^{-}$than in $[\text { DIH1 }]^{+} \cdots[\text { AHA }]^{-}$, according to both $\mathrm{O} \cdots \mathrm{O}$ and $\mathrm{O} \cdots \mathrm{H}$ distances.

\section{(f) Dihydrogen-dihydride $\rightarrow$ Tetrahydride interconversion in the ion pair}

To solve the dichotomy between easy protonation at the hydride site and no detection of dihydrogen intermediates, we have studied the interconversion from the $[\mathbf{D I H} 1]^{+} \ldots[\mathbf{X H X}]^{-}$ to the $[\text { TETRA1 }]^{+} \ldots[\mathbf{X H X}]^{-}$ion pair. As in previous studies of dihydrogen $\rightarrow$ dihydride interconversions, ${ }^{[26]}$ we have chosen the $\mathrm{H}-\mathrm{H}$ distance as a reaction coordinate for the $\mathrm{H}-\mathrm{H}$ bond breaking. This distance varies from $0.884 \AA$ in the dihydrogen structure to $1.812 \AA$ in the tetrahydride. For each fixed value of the reaction coordinate all the other geometrical parameters, including those of the homoconjugate anion, were optimized. The profiles in dichloromethane solvent were obtained from single-point calculations on each point of the gas phase profiles with the solvent PCM. The energy of the dihydrogen ion pair was taken as the zero of energy. The energetic profiles in gas phase and $\mathrm{CH}_{2} \mathrm{Cl}_{2}$ are depicted in Figure 14. 
The calculations illustrate that the dihydrogen-dihydride $\rightarrow$ tetrahydride rearrangement in the ion pairs easily takes place. The energy barrier is only $1.8 \mathrm{kcal} \mathrm{mol}^{-1}$ in gas phase and $1.3 \mathrm{kcal} \mathrm{mol}^{-1}$ in $\mathrm{CH}_{2} \mathrm{Cl}_{2}$. The homoconjugate anion does not change appreciably its position along the interconversion, as proved by the evolution of the $\mathrm{H} \cdots \mathrm{O}$ distance (from $1.359 \AA$ in the dihydrogen structure to $1.241 \AA$ in the tetrahydride). The process is exoergic, ending up in a tetrahydride ion pair $1.5 \mathrm{kcal} \mathrm{mol}^{-1}$ more stable than the initial dihydrogen in the gas phase $\left(-1.7 \mathrm{kcal} \mathrm{mol}^{-1}\right.$ in $\left.\mathrm{CH}_{2} \mathrm{Cl}_{2}\right)$. The solvent influence in this process is very small because it does not involve a charge change.

\section{(h) Dihydrogen evolution}

We have theoretically studied the successive elimination of two $\mathrm{H}_{2}$ molecules in the model $\left[\mathrm{CpMo}(\mathrm{dpe}) \mathrm{H}_{3}\right]-\mathrm{TFE}$ system. The results are graphically assembled in Figure 15 and discussed only briefly here. More details can be found in the Supporting Information. The significant difference between the results in the gas phase and in $\mathrm{CH}_{2} \mathrm{Cl}_{2}$ can be attributed to the solvation of the free TFE molecules (note that the gap is about twice greater when both molecules have been consumed, relative to the intermediate situations where only one has been consumed). The results show that the first $\mathrm{H}_{2}$ elimination, affording the $\left[\mathrm{CpMo}(\mathrm{dpe}) \mathrm{H}_{2}\left(\mathrm{OR}_{\mathrm{F}}\right)\right]$ intermediate (unobserved for the real system), is less favorable than the process leading to loss of two $\mathrm{H}_{2}$ molecules. Note also that the $\mathrm{H}_{2}$ elimination process will further benefit from an entropic drive. Furthermore, the subsequent addition of a second alcohol molecule, to afford the 18-electron adduct, results in a significant stabilization. At least part of this stabilization may be attributed to the intramolecular hydrogen bond. Thus, the calculations point to the identity of the final product as a solvated species. It is also of interest to mention that the 16-electron $\left[\mathrm{CpMo}(\mathrm{dpe})\left(\mathrm{OR}_{\mathrm{F}}\right)\right]$ intermediate prefers to adopt a singlet ground state (the triplet is higher in energy by 6.5 and $7.3 \mathrm{kcal} \mathrm{mol}^{-1}$ in the gas phase 
and in solution, respectively). On the other hand, a parallel calculation on $\left[\mathrm{CpMo}\left(\mathrm{PMe}_{3}\right)_{2}(\mathrm{OH})\right]$ shows that the triplet is $2.3 \mathrm{kcal} \mathrm{mol}^{-1}$ lower than the singlet, in agreement with the experimental observation or paramagnetism for this molecule. ${ }^{[19-20]}$

$<$ Figure 15>

\section{Discussion}

It has been shown in previous spectroscopic ${ }^{[5,27]}$ and theoretical ${ }^{[6,7 b, 28]}$ studies of monohydride compounds that the MH॰• HX interaction weakens the MH bond (low frequency shift for the M-H stretching vibration), whereas the HM $\bullet \bullet H X$ interaction strengthens it (high frequency shift). The present contribution reports the first detailed analysis of the effect of hydrogen bonding on the M-H stretching vibrations for a polyhydride compound where the individual M-H stretching components are heavily mixed into the normal modes. A first outcome of this investigation is that the variation of the vibrational frequencies can be predicted, in most cases, by extension of the previously established trends for monohydride complexes: $^{[4]}$ normal modes whose main contribution is from $\mathrm{M}-\mathrm{H}$ vibrations where the hydride is directly implicated in hydrogen bonds as a proton acceptor experience a lowfrequency shift. Conversely, normal modes whose main contribution is from $\mathrm{M}-\mathrm{H}$ vibrations where the hydride is not directly implicated in hydrogen bonds (either the metal center or other hydride ligands act as the proton acceptor site) experience a low-frequency shift. However, the contribution of various $\mathrm{M}-\mathrm{H}$ stretching vibrations, some of which may be proton acceptors in hydrogen bonds while others may not, in the normal modes calls for a more detailed and in-depth analysis. 
Secondly, the existence, in the present case, of additional interactions with other neighboring proton accepting sites may be the major cause of the complicated changes found like e.g. the changes of certain Mo-H bond lengths which are found to be opposite to expectations based on $\mathrm{H} \bullet \bullet \mathrm{H}$ distances (e.g. shortening of Mo-H2 in B1, lengthening of Mo$\mathrm{H} 2$ in C). An interaction involving exclusively the metal center, without involvement of at least secondary interactions with hydride ligands, does not occur for this compound. It can be easily imagined, by extrapolation, that a direct hydrogen bond with a metal site may be difficult in general, if not impossible, when the system has a relatively crowded coordination sphere and especially when more than one hydride ligand is present. Also, the same circumstances may favor the establishment of simultaneous interactions with more than one hydride ligand.

The computational study allows to reproduce rather well the experimentally determined hydrogen bond enthalpy for the $\left[\mathrm{Cp}^{*} \mathrm{Mo}(\mathrm{dppe}) \mathrm{H}_{3}\right] \cdot \mathrm{TFE}$ interaction by use of the $\left[\mathrm{CpMo}(\mathrm{dpe}) \mathrm{H}_{3}\right]$ model system. The calculations also indicate that the most stable hydrogen bonded adducts between $\left[\mathrm{CpMo}(\mathrm{dpe}) \mathrm{H}_{3}\right]$ and TFE are complexes $\mathbf{B}$, where the proton donor approaches the complex from the side of the molecule containing hydrides $\mathrm{H} 1$ and $\mathrm{H} 2$. Structure B3, which yields the lowest energy minimum, is also the model structure that best reproduces the experimentally observed frequency shifts: the $v_{2}$ band experiences a large lowfrequency shift and appears $3 \mathrm{~cm}^{-1}$ lower than $v_{3}$ mode in free trihydride, whereas the $v_{3}$ band experiences a large high-frequency shift, ending up near the position of the $v_{2}$ mode in free trihydride (compare Figure 8 and Figure 10). The composition of the normal modes is in agreement with this interpretation (the low frequency band in $\mathbf{B 3}$ has the major component from the Mo-H2 vibration, whereas the low frequency band in the free trihydride is mostly a Mo-H3 vibration). The other structural models of the hydrogen bonded adduct (A, B1, B2 and $\mathbf{C}$ ) yield calculated normal mode frequency patterns in greater discrepancy with the 
experiment. In conclusion, it seems that the proton donor approaches the complex from the side of the molecule containing the hydrides $\mathrm{H} 1$ and $\mathrm{H} 2$, and establishes a hydrogen bond with the hydride $\mathrm{H} 2$.

One interesting issue for proton transfer reactions to hydride molecules is the number of proton donor molecules that are involved in proton transfer. Although the involvement of only one molecule should be sufficient in principle, it has been shown in several cases that the protonation product contains the homoconjugate anion, therefore implicating two proton donor molecules in the reaction stoichiometry. ${ }^{[2 f, 7 a, 7 b]}$ It was also shown by kinetics investigations that a second proton donor molecule is necessary to trigger proton transfer from fluorinated alcohols to the hydride complex $[\mathrm{Cp} * \mathrm{Fe}(\mathrm{dppe}) \mathrm{H}] .{ }^{[6,16]}$ On the other hand, when the stronger acid $\mathrm{CF}_{3} \mathrm{COOH}$ was used with the same hydride system, even a single acid molecule was sufficient to transfer the proton. Theoretical calculations have also shown that the involvement of a second proton donor (HX) molecule strengthens hydrogen bonding of the first HA molecule with the proton acceptor in the MH $\cdots \mathrm{HX} \cdots \mathrm{HX}$ adduct.

The basicity of the hydride ligand of $\mathrm{Cp}^{*} \mathrm{MoH}_{3}(\mathrm{dppe})\left(\mathrm{E}_{\mathrm{j}}=1.42 \pm 0.02\right)$ is higher than that of trihydride complexes studied previously (compare with $\mathrm{E}_{\mathrm{j}}$ of 0.93 for $\mathrm{Cp}_{2} \mathrm{NbH}_{3}{ }^{[7 \mathrm{c}]}$ and 0.94 for $\mathrm{Cp}^{*} \mathrm{RuH}_{3}\left(\mathrm{PCy}_{3}\right)^{[29]}$ and is among highest reported in the literature. ${ }^{[4 \mathrm{~b}]}$ Consequently, it can be protonated by such weak acid as TFE. Two separate experiments on the proton transfer process indicate that complex $\mathrm{Cp}^{*} \mathrm{MoH}_{3}(\mathrm{dppe})$ is able to accept a proton from a single molecule of proton donor, at least from donors as weak as HFIP. The UV-visible study of the $\mathrm{Cp}^{*} \mathrm{MoH}_{3}(\mathrm{dppe})-\mathrm{PNP}\left(\mathrm{P}_{\mathrm{i}}=1.27\right)$ interaction shows a breakpoint at a $1: 1$ ratio and a visible band consistent with the formation of the $\left[\mathrm{Cp} *(\mathrm{dppe}) \mathrm{MoH}_{4}\right]^{+} \ldots[\mathrm{OAr}]^{-}$ion pair. On the other hand, the kinetic study of the $\mathrm{Cp}^{*} \mathrm{MoH}_{3}(\mathrm{dppe})$-HFIP $\left(\mathrm{P}_{\mathrm{i}}=1.05\right)$ interaction illustrates the need of only one HFIP molecule to reach the transition state for proton transfer. This situation markedly differs from that previously established for the protonation of the less 
basic hydride ligand in complex $[\mathrm{Cp} * \mathrm{Fe}(\mathrm{dppe}) \mathrm{H}]\left(\mathrm{E}_{\mathrm{j}}=1.35 \pm 0.02\right)$, where a second molecule is necessary. ${ }^{[16]}$ Interestingly, the formation of hydrogen bonded ion pairs is not only evident from the UV-visible study of the $\mathrm{Cp}^{*} \mathrm{MoH}_{3}$ (dppe)-PNP system, but also from the ${ }^{1} \mathrm{H}$ NMR data through the different $\mathrm{T}_{1}$ values obtained for the TFE and $\mathrm{HBF}_{4}$ protonation products (Table 2), although the latter result cannot distinguish between the simple $\left(\mathrm{X}^{-}\right)$and the homoconjugate $\left(\mathrm{XHX}^{-}\right)$anion.

The low-temperature NMR study does not show any evidence for the formation of a dihydrogen intermediate, whereas the low-temperature IR study suggests that the preferred hydrogen bonding pathway involves the hydride ligand. Thus, an intermediate dihydrogen complex along the proton transfer pathway may be expected. The computational investigation suggests that, both in gas phase and in dichloromethane, the tetrahydride ion pair resulting from the protonation at the metal site is more stable than the dihydrogen-dihydride ion pair arising from the hydride protonation, in agreement with the experiment. Both proton transfer pathways leading to hydride and metal protonation show low barriers, in agreement with the experimental evidence of a very fast process. However, these values are rather similar (9.4 and $10.2 \mathrm{kcal} \mathrm{mol}^{-1}$ for proton transfer from the HFIP dimer in $\mathrm{CH}_{2} \mathrm{Cl}_{2}$ ), indicating that in this molybdenum trihydride there is no clear kinetic preference for the protonation at the hydride site. This theoretical result contrasts with the commonly admitted kinetic preference for the protonation at the hydride site, and with a recent theoretical study of the protonation of $\mathrm{CpFe}(\mathrm{dpe}) \mathrm{H}$ with two HFIP molecules. ${ }^{[6]}$

If the non-classical intermediate indeed forms during the proton transfer process, its activation barrier to the rearrangement leading to the classical tetrahydride product must be very low. Indeed, a very low barrier for the rearrangement of the model compounds $\left([\mathbf{D I H 1}]^{+} \ldots[\mathbf{X H X}]^{-}\right.$to $[\text {TETRA1 }]^{+} \ldots[\mathbf{X H X}]^{-}$where $\left.\mathrm{HX}=\mathrm{HFIP}\right)$ is shown by the 
calculations. Note that this rearrangement does not necessitate any ion pair dissociation, since the anion does not change appreciably its position along the interconversion.

To summarize, the tetrahydride product can originate either from the direct protonation at the metal site or from the fast isomerization of the dihydrogen intermediate and the available experimental and theoretical results do not allow us to clearly distinguish these two possibilities. The involvement of a transient dihydrogen species in the formation of trihydride by protonation of a transition metal dihydride has been reported in a mechanistic study of the protonation of $\mathrm{Cp}_{2} \mathrm{MH}_{2}(\mathrm{M}=\mathrm{Mo}, \mathrm{W})$ by an excess of anhydrous $\mathrm{HCl}^{[30]}$

\section{Conclusions}

The unambiguous determination of the hydrogen bonding site for a polyhydride compound by NMR and IR spectroscopic techniques is not an easy task. The high fluxionality of polyhydride complexes on the NMR time scale renders the application of this method less straightforward, while the use of vibrational spectroscopy is complicated by the normal mode structure and weak intensity of the M-H stretching bands. The theoretical analysis of the vibrational modes, which was performed here for the first time for a transition metal polyhydride compound in the absence and presence of hydrogen bonding, shows a different behavior for each M-H vibrational normal mode. Nevertheless, the evolution of the vibrational frequencies follows in most cases the trends previously established for monohydride complexes: a low-frequency shift for modes that primarily involve the $\mathrm{M}-\mathrm{H}$ vibrations where the $\mathrm{H}$ ligand is implicated in the hydrogen bond and a high-frequency shift for modes that primarily involve $\mathrm{M}-\mathrm{H}$ vibrations where the $\mathrm{H}$ ligand is not implicated in the hydrogen bond (hydrogen bonding to other hydride ligands or to the metal atom). According to the calculations the most stable hydrogen bonded adducts are those where the proton donor 
approaches the $\mathrm{Cp}^{*} \mathrm{MoH}_{3}(\mathrm{dppe})$ complex from the side of the molecule containing the hydrides $\mathrm{H} 1$ and $\mathrm{H} 2$. Of these, the one giving a good agreement with the experimental IR observations features a hydrogen bond with $\mathrm{H} 2$.

Dihydrogen bond formation precedes the proton transfer to form the cationic tetrahydride $\left[\mathrm{Cp} *(\mathrm{dppe}) \mathrm{MoH}_{4}\right]^{+}$complex, stabilized by hydrogen bonding to the proton donor conjugate base. This is reversible at low temperatures (below $250 \mathrm{~K}$ ) when using $p$-nitrophenol or TFE. The precursor $\mathrm{Cp}^{*}(\mathrm{dppe}) \mathrm{MoH}_{3}$ complex is sufficiently basic to accept the proton from a single molecule of these two proton donors.

The experiments do not show any direct evidence for the formation of a dihydrogen intermediate, whereas the preferred hydrogen bonding pathway, according to the computational study, appears to involve the hydride ligand. The intermediacy of a dihydrogen complex along the proton transfer pathway is possible, as suggested by the computations. However, the calculated low barrier for its isomerization into the classical tetrahydride complex would rationalize our unability to observe it experimentally.

\section{Experimental section}

General. All manipulations were carried out under an argon atmosphere by standard Schlenk techniques. The $\left[\mathrm{Cp} * \mathrm{Mo}(\mathrm{dppe}) \mathrm{H}_{3}\right]$ hydride was synthesized according to the literature. ${ }^{[8]}$ All solvents used $\left(\mathrm{CH}_{2} \mathrm{Cl}_{2}\right.$, THF, toluene) have been dried using appropriate agents and freshly distilled prior to use.

IR and UV-visible investigations. The IR measurements were performed on a “Specord M82" and Infralum FTIR-81 (Lumex) spectrometers using $\mathrm{CaF}_{2}$ cells $(0.12 \mathrm{~cm}$ path length). In order to limit the significance of self-association phenomena, a concentration of the proton donor between 0.005 and $0.01 \mathrm{M}$ was used for the $v(\mathrm{OH})$ measurements. The UV 
measurements were performed on Specord M-40 and Varian Cary 5 spectrophotometers. Low temperature IR and UV measurements were carried out by use of a cryostat (Carl Zeiss Jena) in the $200-290 \mathrm{~K}$ temperature range. The accuracy of the temperature adjustment was $\pm 0.5 \mathrm{~K}$. The reagents were mixed at low temperature and the cold mixtures were subsequently transferred into the pre-cooled cryostat.

NMR investigations. The NMR studies were carried out in standard $5 \mathrm{~mm}$ NMR tubes containing solutions of the complexes in $\mathrm{CD}_{2} \mathrm{Cl}_{2}$. The ${ }^{1} \mathrm{H}$ and ${ }^{31} \mathrm{P}$ NMR data were collected with a Bruker AMX 400 spectrometer operating at 400.13 and $161.98 \mathrm{MHz}$, respectively. The conventional inversion-recovery-pulse method (180- $\tau-90)$ was used to determine the variabletemperature longitudinal relaxation time $T_{1}$. Low temperature experiments were carried out in the 180-260 K temperature range using a TV-3000 Bruker temperature control unit. The accuracy and stability of temperature was $\pm 1 \mathrm{~K}$. All mixings between the alcohols and the hydride complexes were performed at low temperature.

Stopped-Flow Investigations. The stopped-flow kinetic runs were carried out at $293 \mathrm{~K}$ with a Bio-Logic SF20 apparatus coupled to a J\&M TIDAS MMS-UV/VIS diode-array UVvisible spectrophotometer using a cuvette with a $0.15 \mathrm{~cm}$ pathlength. The data were collected within the first $10 \mathrm{~s}$, yielding reproducible results. Data analyses were carried out by using the SPECFIT3 global analysis package of programs. ${ }^{[31]}$ At least three runs were averaged to yield the reported results.

Computational details. Calculations were performed with the Gaussian98 ${ }^{[32]}$ package at the DFT/B3LYP level. ${ }^{[33]}$ Effective core potentials (ECP) were used to represent the innermost electrons of the molybdenum atom as well as the electron core of phosphorous atoms. ${ }^{[34]}$ The basis set for the Mo and $\mathrm{P}$ atoms was that associated with the pseudopotential, ${ }^{[34]}$ with a standard double- $\zeta$ LANL2DZ contraction, ${ }^{[32]}$ supplemented in the case of $\mathrm{P}$ with a set of dpolarization functions. ${ }^{[35]}$ The carbon and hydrogen atoms of the transition metal complexes 
that are not bonded to the metal atom, together with the atoms of proton donor molecules $(\mathrm{C}$, $\mathrm{F}, \mathrm{H})$ that are not involved in hydrogen bonds, were described with a $6-31 \mathrm{G}$ basis set. ${ }^{[36]}$ The carbon and hydrogen atoms directly bonded to the metal and the proton donor molecules hydrogen and oxygen atoms involved in hydrogen bonding were described with a 6-31G(d,p) set of basis functions. ${ }^{[37]}$ Geometry optimizations were carried out without symmetry restrictions and the resulting structures were characterized as minima by the real value of all 3 N-6 vibrational frequencies. Solvent effects were taken into account by means of polarized continuum model $(\mathrm{PCM})$ calculations, ${ }^{[38]}$ using standard options. ${ }^{[32]}$ The solvation free energies were computed in dichloromethane $(\varepsilon=8.93)$ at the gas phase optimized geometries. The gas phase complexation energies were corrected from the basis set superposition error according to the counterpoise method of Boys and Bernardi. ${ }^{[39]}$

\section{Acknowledgement}

We thank the European Commission through the HYDROCHEM program (contract HPRN-CT-2002-00176) for support of this work. Additional bilateral support (PICS, FranceRussia) and National support from the CNRS (France), from the RFBR (05-03-22001, 05-0332415) and the Division of Chemistry and Material Sciences of RAS (Russia), and from MEC (project CTQ2005-09000-CO2-01; Spain) is also gratefully acknowledged. AL thanks the Generalitat de Catalunya for a Distinció per a la Promocio de la Recerca Universitària. NB thanks Russian Science Support Foundation for an individual grant. MB thanks the Spanish Ministerio de Educación y Ciencia for a post-doctoral fellowship.

\section{Supporting Information.}

Table of optimized geometrical parameters for $\left[\mathrm{CpMo}(\mathrm{dpe}) \mathrm{H}_{3}\right]$ and $\left[\mathrm{CpMo}(\mathrm{dpe}) \mathrm{H}_{4}\right]^{+}$ complexes, views of optimized $\left[\mathrm{Cp} * \mathrm{Mo}(\mathrm{dppe}) \mathrm{H}_{3}\right],\left[\mathrm{Cp} * \mathrm{Mo}(\mathrm{dppe}) \mathrm{H}_{4}\right]^{+}$, and a variety of 
dihydrogen bonded adducts, and a description of computational results on the $\mathrm{H}_{2}$ elimination process from $\left[\mathrm{CpMo}(\mathrm{dpe}) \mathrm{H}_{4}\right]^{+}(7$ pages $)$.

\section{References}

[1] aM. Peruzzini, R. Poli, Recent Advances in Hydride Chemistry, Elsevier, Amsterdam, 2001; bV. I. Bakhmutov, Eur. J. Inorg. Chem. 2005, 245-255.

[2] aG. Parkin, J. E. Bercaw, J. Chem. Soc., Chem. Commun. 1989, 255-257; bM. S. Chinn, D. M. Heinekey, J. Am. Chem. Soc. 1990, 112, 5166-5175; cG. Jia, A. J. Lough, R. H. Morris, Organometallics 1992, 11, 161-171; dP. Hamon, L. Toupet, J.R. Hamon, C. Lapinte, Organometallics 1992, 11, 1429-1431; eJ. R. Hamon, P. Hamon, L. Toupet, K. Costuas, J. Y. Saillard, C. R. Chim. 2002, 5, 89-98; fE. T. Papish, F. C. Rix, N. Spetseris, J. R. Norton, R. D. Williams, J. Am. Chem. Soc. 2000, 122, 12235-12242; gE. T. Papish, M. P. Magee, J. R. Norton, in Recent Advances in Hydride Chemistry (Eds.: M. Peruzzini, R. Poli), Elsevier, Amsterdam, 2001, pp. 3974.

[3] aE. S. Shubina, A. N. Krylov, N. V. Belkova, L. M. Epstein, A. P. Borisov, V. D. Mahaev, J. Organometal. Chem. 1995, 493, 275-277; bA. Albinati, V. I. Bakhmutov, N. V. Belkova, C. Bianchini, I. de los Rios, L. Epstein, E. I. Gutsul, L. Marvelli, M. Peruzzini, R. Rossi, E. S. Shubina, E. V. Vorontsov, F. Zanobini, Eur. J. Inorg. Chem. 2002, 1530-1539.

[4] aL. M. Epstein, N. V. Belkova, E. S. Shubina, in Recent Advances in Hydride Chemistry (Eds.: M. Peruzzini, R. Poli), Elsevier, Amsterdam, 2001, pp. 391-418; bL. M. Epstein, E. S. Shubina, Coord. Chem. Rev. 2002, 231, 165-181.

[5] N. V. Belkova, E. S. Shubina, L. M. Epstein, Acc. Chem. Res. 2005, 38, 624-631.

[6] N. V. Belkova, E. Collange, P. Dub, L. M. Epstein, D. A. Lemenovskii, A. Lledós, O. Maresca, F. Maseras, R. Poli, P. O. Revin, E. S. Shubina, E. V. Vorontsov, Chem. Eur. J. 2005, 11, 873-888.

[7] aN. V. Belkova, A. V. Ionidis, L. M. Epstein, E. S. Shubina, S. Gruendemann, N. S. Golubev, H. H. Limbach, Eur. J. Inorg. Chem. 2001, 1753-1761; bN. Belkova, M. Besora, L. Epstein, A. Lledós, F. Maseras, E. Shubina, J. Am. Chem. Soc. 2003, 125, 7715-7725; cE. Bakhmutova, V. Bakhmutov, N. Belkova, M. Besora, L. Epstein, A. Lledós, G. Nikonov, E. Shubina, J. Tomas, E. Vorontsov, Chem. Eur. J. 2004, 10, 661-671.

[8] B. Pleune, R. Poli, J. C. Fettinger, Organometallics 1997, 16, 1581-1594.

[9] J. C. Fettinger, B. Pleune, R. Poli, J. Am. Chem. Soc. 1996, 118, 4906-4907.

[10] J. Andrieu, N. V. Belkova, M. Besora, E. Collange, L. M. Epstein, A. Lledós, R. Poli, P. O. Revin, E. S. Shubina, E. V. Vorontsov, Russ. Chem. B. 2003, 52, 2679-2682.

[11] J. Andrieu, N. V. Belkova, M. Besora, E. Collange, L. M. Epstein, A. Lledós, R. Poli, P. O. Revin, E. S. Shubina, E. V. Vorontsov, to be published.

[12] E. Gutsul, N. Belkova, M. Sverdlov, L. Epstein, E. Shubina, V. Bakhmutov, T. Gribanova, R. Minyaev, C. Bianchini, M. Peruzzini, F. Zanobini, Chem. Eur. J. 2003, 9, 2219-2228.

[13] R. B. Girling, P. Grebenik, R. N. Perutz, Inorg. Chem. 1986, 25, 31-36.

[14] R. H. Crabtree, D. G. Hamilton, Adv. Organometal. Chem. 1988, 28, 299-338. 
[15] E. I. Gutsul, N. V. Belkova, G. M. Babakhina, L. M. Epstein, E. S. Shubina, C. Bianchini, M. Peruzzini, F. Zanobini, Russ. Chem. Bull. 2003, 52, 1204-1206.

[16] N. V. Belkova, P. O. Revin, L. M. Epstein, E. V. Vorontsov, V. I. Bakhmutov, E. S. Shubina, E. Collange, R. Poli, J. Am. Chem Soc. 2003, 125, 11106-11115.

[17] M. Luksza, S. Kimmer, W. Malisch, Angew. Chem. Int. Ed. 1983, 22, 416-417.

[18] R. T. Baker, J. C. Calabrese, R. L. Harlow, I. D. Williams, Organometallics 1993, 12, 830-841.

[19] R. Poli, E. A. Quadrelli, New J. Chem. 1998, 22, 435-450.

[20] J. C. Fettinger, H.-B. Kraatz, R. Poli, E. A. Quadrelli, Chem. Commun. 1997, 889-890.

[21] T. J. Johnson, A. Albinati, T. F. Koetzle, J. Ricci, O. Eisenstein, J. C. Huffman, K. G. Caulton, Inorg. Chem. 1994, 33, 4966-4976.

[22] F. Maseras, A. Lledós, M. Costas, J. M. Poblet, Organometallics 1996, 15, 2947-2953.

[23] A. V. Iogansen, Theor. Experim. Khim., 1971, 7, 312-317.

[24] A. V. Iogansen, Spectrochim. Acta A 1999, 55, 1585-1612.

[25] M. H. Baik, R. A. Friesner, J. Phys. Chem. A 2002, 106, 7407-7412.

[26] J. Tomàs, A. Lledós, Y. Jean, Organometallics 1998, 17, 4932-4939.

[27] L. M. Epstein, N. V. Belkova, E. I. Gutsul, E. S. Shubina, Polish Journal of Chemistry 2003, 77, 1371-1383.

[28] G. Orlova, S. Scheiner, J. Phys. Chem. A 1998, 102, 260-269.

[29] N. V. Belkova, L. Epstein, E. S. Shubina, unpublished observations.

[30] R. A. Henderson, K. E. Oglieve, Journal of the Chemical Society, Dalton Transactions: Inorganic Chemistry (1972-1999) 1993, 3431-3439.

[31] R. A. Binstead, A. D. Zuberbühler, B. Jung, Specfit/32 v. 3.0.36, Spectrum Software Associates, Chapel Hill, NC, 2004.

[32] M. J. Frisch, G. W. Trucks, H. B. Schlegel, G. E. Scuseria, M. A. Robb, J. R.

Cheeseman, V. G. Zakrzewski, J. Montgomery, J. A., R. E. Stratmann, J. C. Burant, S. Dapprich, J. M. Millam, A. D. Daniels, K. N. Kudin, M. C. Strain, O. Farkas, J. Tomasi, V. Barone, M. Cossi, R. Cammi, B. Mennucci, C. Pomelli, C. Adamo, S. Clifford, J. Ochterski, G. A. Petersson, P. Y. Ayala, Q. Cui, K. Morokuma, D. K. Malick, A. D. Rabuck, K. Raghavachari, J. B. Foresman, J. Cioslowski, J. V. Ortiz, A. G. Baboul, B. B. Stefanov, G. Liu, A. Liashenko, P. Piskorz, I. Komaromi, R. Gomperts, R. L. Martin, D. J. Fox, T. Keith, M. A. Al-Laham, C. Y. Peng, A. Nanayakkara, C. Gonzalez, M. Challacombe, P. M. W. Gill, B. Johnson, W. Chen, M. W. Wong, J. L. Andres, C. Gonzalez, M. Head-Gordon, E. S. Replogle, J. A. Pople, Gaussian 98, Revision A.9, Gaussian, Inc., Pittsburgh PA, 1998.

[33] aC. T. Lee, W. T. Yang, R. G. Parr, Phys. Rev. B 1988, 37, 785-789; bA. D. Becke, J. Chem. Phys. 1993, 98, 5648-5652; cP. STEPHENS, F. DEVLIN, C.

CHABALOWSKI, M. FRISCH, J. Phys. Chem. 1994, 98, 11623-11627.

[34] aW. R. Wadt, P. J. Hay, J. Chem. Phys. 1985, 82, 284-298; bP. J. Hay, W. R. Wadt, J. Chem. Phys. 1985, 82, 299-310.

[35] A. HÖLLWARTH, M. BOHME, S. DAPPRICH, A. EHLERS, A. GOBBI, V. JONAS, K. KOHLER, R. STEGMANN, A. VELDKAMP, G. FRENKING, Chemical Physics Letters 1993, 208, 237-240.

[36] W. Hehre, R. Ditchfie, J. Pople, J. Chem. Phys. 1972, 56, 2257-2261.

[37] P. HARIHARA, J. POPLE, Theoretica Chimica Acta 1973, 28, 213-222.

[38] aJ. Tomasi, M. Persico, Chem. Rev. 1994, 94, 2027-2094; bC. Amovilli, V. Barone, R. Cammi, E. Cancès, M. Cossi, B. Menucci, C. S. Pomelli, J. Tomasi, Adv. Quantum Chem. 1998, 32, 227-261. 
[39] S. F. Boys, F. Bernardi, Mol. Phys. 1970, 19, 553-566. 
Table 1. Parameters of the dihydrogen bonding between $\left[\mathrm{Cp} * \mathrm{Mo}(\mathrm{dppe}) \mathrm{H}_{3}\right]$ and $\mathrm{MFE}$ or TFE, and basicity factors.

\begin{tabular}{cccccccc}
\hline ROH & $\begin{array}{c}v_{\mathrm{OH}(\mathrm{free})} \\
\mathrm{cm}^{-1}\end{array}$ & $\begin{array}{c}v_{\mathrm{OH}(\mathrm{bonded})} \\
\mathrm{cm}^{-1}\end{array}$ & $\begin{array}{c}\Delta v \\
\mathrm{~cm}^{-1}\end{array}$ & $\begin{array}{c}\Delta \mathrm{H}_{\mathrm{HB}^{\mathrm{a}}} \\
\mathrm{kcal} \mathrm{mol}^{-1}\end{array}$ & $\begin{array}{c}\Delta \mathrm{H}_{\mathrm{HB}} \mathrm{b}^{-1} \\
\mathrm{kcal} \mathrm{mol}^{-1}\end{array}$ & $\begin{array}{c}\Delta \mathrm{S}_{\mathrm{HB}}{ }^{\mathrm{b}} \\
\mathrm{cal} \mathrm{mol}^{-1} \mathrm{~K}^{-1}\end{array}$ & $\mathrm{E}_{\mathrm{j}}$ \\
\hline MFE & 3612 & 3368 & 244 & -4.9 & $-4.9 \pm 0.2$ & $-15.7 \pm 0.7$ & 1.44 \\
TFE & 3604 & 3248 & 364 & -5.9 & $-6.1 \pm 0.3$ & $-20.4 \pm 1$ & 1.41 \\
\hline
\end{tabular}

Table 2. Longitudinal relaxation time $\mathrm{T}_{1 \text { min }}(\mathrm{ms})$ for $\left[\mathrm{Cp} * \mathrm{Mo}(\mathrm{dppe}) \mathrm{H}_{3}\right]$ in $\mathrm{CD}_{2} \mathrm{Cl}_{2}$ solution under different conditions. ${ }^{\mathrm{a}}$

\begin{tabular}{lccc}
\hline & $T_{\min }(\mathrm{K})$ & {$\left[\mathrm{Cp} * \mathrm{Mo}(\mathrm{dppe}) \mathrm{H}_{3}\right]$} & {$\left[\mathrm{Cp}^{*} \mathrm{Mo}(\mathrm{dppe}) \mathrm{H}_{4}\right]^{+}$} \\
\hline free & 220 & 302 & \\
$+\mathrm{HBF}_{4}$ (1 equiv) & $230^{\mathrm{b}}$ & 274 & 174 \\
$+\mathrm{TFE}$ (6 equiv) & $230^{\mathrm{b}}$ & 295 & 191 \\
\hline
\end{tabular}

${ }^{\mathrm{a}}$ At $400 \mathrm{MHz} .{ }^{\mathrm{b}}$ The resonances of both complexes have a minimum $\mathrm{T}_{1}$ at the same temperature.

Table 3. Relevant optimized geometrical parameters (distances in $\AA$; angles in degrees) for $\left[\mathrm{CpMo}(\mathrm{dpe}) \mathrm{H}_{3} \cdots \mathrm{TFE}\right](\mathbf{A}-\mathbf{C})$ adducts. $^{\mathrm{a}}$

\begin{tabular}{lccccc}
\hline & A & B1 & B2 & B3 & C \\
\hline Mo-H1 $^{\text {b }}$ & 1.678 & 1.687 & 1.684 & 1.682 & 1.680 \\
& $(-0.004)$ & $(+0.005)$ & $(+0.002)$ & $(0.000)$ & $(-0.002)$ \\
Mo-H2 $^{\text {b }}$ & 1.722 & 1.713 & 1.725 & 1.736 & 1.725 \\
& $(+0.005)$ & $(-0.004)$ & $(+0.008)$ & $(+0.019)$ & $(+0.008)$ \\
Mo-H3 $^{\text {b }}$ & 1.734 & 1.724 & 1.720 & 1.717 & 1.731 \\
& $(+0.010)$ & $(0.000)$ & $(-0.004)$ & $(-0.007)$ & $(+0.007)$ \\
O-H & 0.977 & 0.980 & 0.977 & 0.979 & 0.979 \\
$\mathrm{H} \cdots \mathrm{H} 1$ & $(+0.012)$ & $(+0.015)$ & $(+0.012)$ & $(+0.014)$ & $(+0.014)$ \\
$\mathrm{H} \cdots \mathrm{H} 2$ & & 2.057 & 1.944 & 2.942 & \\
$\mathrm{H} \cdots \mathrm{H} 3$ & 1.816 & 1.779 & 1.799 & 1.653 & \\
$\mathrm{H} \cdots \mathrm{Mo}$ & 3.068 & 2.927 & 3.034 & 2.987 & 2.864 \\
$\mathrm{O}-\mathrm{H} \cdots \mathrm{H} 1$ & & 152.5 & 148.5 & 147.1 & \\
$\mathrm{O}-\mathrm{H} \cdots \mathrm{H} 2$ & & 150.1 & 150.6 & 160.3 & \\
$\mathrm{O}-\mathrm{H} \cdots \mathrm{H} 3$ & 155.2 & & & & 140.0 \\
$\mathrm{O}-\mathrm{H} \cdots \mathrm{Mo}$ & 152.9 & 160.4 & 177.8 & 170.4 & 172.4 \\
\hline
\end{tabular}

${ }^{\mathrm{a}}$ For the location of $\mathrm{H} 1, \mathrm{H} 2$ and $\mathrm{H} 3$, see Figure 8.

${ }^{b}$ Values in parentheses are the changes relative to free [CpMo(dpe $\left.) \mathrm{H}_{3}\right]$.

${ }^{c}$ Values in parentheses are the changes relative to free TFE. 
Table 4. Computed Mulliken charges for selected atoms in the $\left[\mathrm{CpMo}(\mathrm{dpe}) \mathrm{H}_{3}\right]$ complex and for its TFE adducts. ${ }^{\mathrm{a}}$

\begin{tabular}{|c|c|c|c|c|c|}
\hline & H(TFE) & Mo & H1 & $\mathrm{H} 2$ & $\mathrm{H} 3$ \\
\hline$\left[\mathrm{CpMo}(\mathrm{dpe}) \mathrm{H}_{3}\right]$ & & -0.316 & -0.017 & -0.003 & -0.053 \\
\hline TFE & 0.326 & & & & \\
\hline A & 0.353 & -0.307 & -0.015 & -0.001 & -0.128 \\
\hline B1 & 0.373 & -0.367 & -0.017 & -0.076 & -0.047 \\
\hline B2 & 0.368 & -0.310 & -0.046 & -0.088 & -0.051 \\
\hline B3 & 0.364 & -0.296 & -0.020 & -0.123 & -0.049 \\
\hline C & 0.373 & -0.422 & -0.010 & 0.002 & -0.072 \\
\hline
\end{tabular}

${ }^{\mathrm{a}}$ For the location of $\mathrm{H} 1, \mathrm{H} 2$ and $\mathrm{H} 3$, see Figure 8

Table 5. Calculated parameters of the hydrogen bonding between $\left[\mathrm{CpMo}(\mathrm{dpe}) \mathrm{H}_{3}\right]$ and TFE.

\begin{tabular}{cccccc}
\hline & A & B1 & B2 & B3 & C \\
\hline$\Delta E / \mathrm{kcal} \mathrm{mol}^{-1}$ & -9.6 & -11.3 & -11.2 & -11.5 & -10.4 \\
$\Delta E(B S S E)^{\mathrm{a}} / \mathrm{kcal} \mathrm{mol}^{-1}$ & -5.1 & -7.9 & -7.8 & -5.9 & -5.9 \\
$\Delta H(B S S E)^{\mathrm{b}} / \mathrm{kcal} \mathrm{mol}^{-1}$ & -3.5 & -6.0 & -6.1 & -5.9 & -4.3 \\
$v(\mathrm{OH}) / \mathrm{cm}^{-1}$ & 3617 & 3553 & 3605 & 3552 & 3576 \\
$\left(10^{-4} \mathrm{~A} / \mathrm{L} \mathrm{mol}^{-1} \mathrm{~cm}^{-2}\right)$ & $(4.99)$ & $(7.25)$ & $(7.15)$ & $(7.77)$ & $(6.23)$ \\
$\Delta H(\Delta v))^{\mathrm{c}} / \mathrm{kcal} \mathrm{mol}^{-1}$ & -4.3 & -5.2 & -4.5 & -5.2 & -4.9 \\
$\Delta H(\Delta \mathrm{A})^{\mathrm{d}} / \mathrm{kcal} \mathrm{mol}^{-1}$ & -4.7 & -5.8 & -6.0 & -6.3 & -5.5 \\
$\Delta G\left(\mathrm{CH}_{2} \mathrm{Cl}_{2}\right)^{\mathrm{e}} / \mathrm{kcal} \mathrm{mol}^{-1}$ & -1.6 & -3.1 & -3.2 & -3.4 & -2.8 \\
\hline
\end{tabular}

${ }^{\mathrm{a}}$ Complexation energy corrected by the basis set superposition error.

${ }^{\mathrm{b}}$ Complexation enthalpy, taking the BSSE-corrected energy.

${ }^{\mathrm{c}}$ Application of Equation 1, ${ }^{[23]}$ using the computed $\Delta v(\mathrm{OH})$.

${ }^{\mathrm{d}}$ Application of Equation 3, ${ }^{[24]}$ using the computed intensities A.

${ }^{\mathrm{e}}$ Complexation free energy in dichloromethane. 


\section{Captions for Figures}

Figure 1. IR spectra in the $v\left(\mathrm{R}_{\mathrm{F}} \mathrm{O}-\mathrm{H}\right)$ stretching region of MFE (1) or TFE (2) in $\mathrm{CH}_{2} \mathrm{Cl}_{2}$ in the presence of $\left[\mathrm{Cp}^{*} \mathrm{Mo}(\mathrm{dppe}) \mathrm{H}_{3}\right]$.

Figure 2. IR spectrum in the $v(\mathrm{Mo}-\mathrm{H})$ stretching region of $\left[\mathrm{Cp}^{*} \mathrm{Mo}(\mathrm{dppe}) \mathrm{H}_{3}\right](0.030 \mathrm{M})$ in $\mathrm{CH}_{2} \mathrm{Cl}_{2}$, after subtraction of the phenyl overtones, showing the band decomposition.

Figure 3. IR spectra in the $v(\mathrm{Mo}-\mathrm{H})$ stretching region of $\left[\mathrm{Cp}^{*} \mathrm{Mo}(\mathrm{dppe}) \mathrm{H}_{3}\right](0.084 \mathrm{M})$ in THF at $200 \mathrm{~K}$. (a) Without proton donor. (b) With HBF4 (1.1 equiv). (c) With HFIP (7 equiv) after subtraction of the HFIP spectrum.

Figure 4. IR spectra in the $v(\mathrm{Mo}-\mathrm{H})$ stretching region of $\left[\mathrm{Cp}^{*} \mathrm{Mo}(\mathrm{dppe}) \mathrm{H}_{3}\right](0.037 \mathrm{M})$ in $\mathrm{CH}_{2} \mathrm{Cl}_{2}$ at $200 \mathrm{~K}$. (a) Without TFE. (b) With TFE (2 equiv). (c) With TFE (5 equiv). (d) With TFE (10 equiv).

Figure 5. Intensity changes at $390 \mathrm{~nm}$ versus the PNP/Mo ratio.

Figure 6. Pseudo-first order rate constants $\left(k_{1 o b s}\right)$ for the proton transfer from HFIP to $\left[\mathrm{Cp} * \mathrm{Mo}(\mathrm{dppe}) \mathrm{H}_{3}\right]$

Figure 7. UV-visible study of the interaction between $\left[\mathrm{Cp}^{*} \mathrm{Mo}(\mathrm{dppe}) \mathrm{H}_{3}\right]$ and TFE (4 equiv) in $\mathrm{CH}_{2} \mathrm{Cl}_{2}$. (a) Initial complex $\mathrm{C}=0.02 \mathrm{M}$. (b) tetrahydride $\mathrm{C}=0.02 \mathrm{M}$. (c) $T=$ $200 \mathrm{~K}$. (d) $T=240 \mathrm{~K}$. The other intermediate spectra were recorded at each $10 \mathrm{~K}$ step.

Figure 8. ORTEP view of the DFT optimized [CpMo(dpe) $\left.\mathrm{H}_{3}\right]$ molecule. The $\mathrm{Cp}$ and $\mathrm{P}$ bonded $\mathrm{H}$ atoms and ethylene backbone have been omitted for clarity. The $\mathrm{M}-\mathrm{H}$ normal modes are represented with their respected computed frequency and intensity $\left(10^{4} \mathrm{~L} \mathrm{~mol}^{-1} \mathrm{~cm}^{-2}\right)$ in parentheses.

Figure 9. Optimized geometries of $\left[\mathrm{CpMo}(\mathrm{dpe}) \mathrm{H}_{3}\right]$ and the $\left[\mathrm{CpMo}(\mathrm{dpe}) \mathrm{H}_{3} \cdots \mathrm{TFE}\right]$ hydrogen-bonded adducts A-C.

Figure 10. ORTEP view of the DFT optimized $\left[\mathrm{CpMo}(\mathrm{dpe}) \mathrm{H}_{3} \cdots \mathrm{TFE}\right]$ adducts, showing selected bonding parameters and a representation of the normal modes with the computed frequency and intensity $\left(\mathrm{A}, 10^{4} \mathrm{~L} \mathrm{~mol}^{-1} \mathrm{~cm}^{-2}\right)$ in parentheses. The $\mathrm{P}$ bonded $\mathrm{H}$ atoms and ethylene backbone have been omitted for clarity. 
Figure 11. Views of the optimized geometries for isomeric structures having the $\left[\mathrm{CpMo}(\mathrm{dpe}) \mathrm{H}_{4}\right]^{+}$stoichiometry.

Figure 12. Potential energy curves for the proton transfer from HFIP to the Mo trihydride at the metal site. Plain curve and squares: in the gas phase; dashed line and triangles: in dichloromethane solution. The $\mathrm{O}-\mathrm{H}$ length of the transferring proton has been taken as the reaction coordinate.

Figure 13. Potential energy curves for the proton transfer from two HFIP molecules to the Mo trihydride: (a) at the metal site; (b) at the hydride site. Plain curves and squares: in the gas phase; dashed lines and triangles: in dichloromethane solution. The $\mathrm{O}-\mathrm{H}$ length of the transferring proton has been taken as the reaction coordinate.

Figure 14. Potential energy curve for the interconversion from the $\left([\mathbf{D I H 1}]^{+} \cdot[\mathbf{X H X}]^{-}\right)$to the ([TETRA1 $]^{+} \cdot[\mathbf{X H X}]^{-}$) ion pairs. Plain curves and squares: in the gas phase; dashed lines and triangles: in dichloromethane solution. The $\mathrm{H}-\mathrm{H}$ length of the coordinated dihydrogen has been taken as the reaction coordinate.

Figure 15. Computed energy profile (solid lines: gas-phase; dashed lines: $\mathrm{CH}_{2} \mathrm{Cl}_{2}$ solution) in $\mathrm{kcal} \mathrm{mol}^{-1}$ for the $\mathrm{H}_{2}$ elimination from complex $\left[\mathrm{CpMo}(\mathrm{dpe}) \mathrm{H}_{3}\right]\left(\mathrm{R}_{\mathrm{F}} \mathrm{OH}=\right.$ TFE). Full details are reported in the Supporting Information. 
(a) Figures

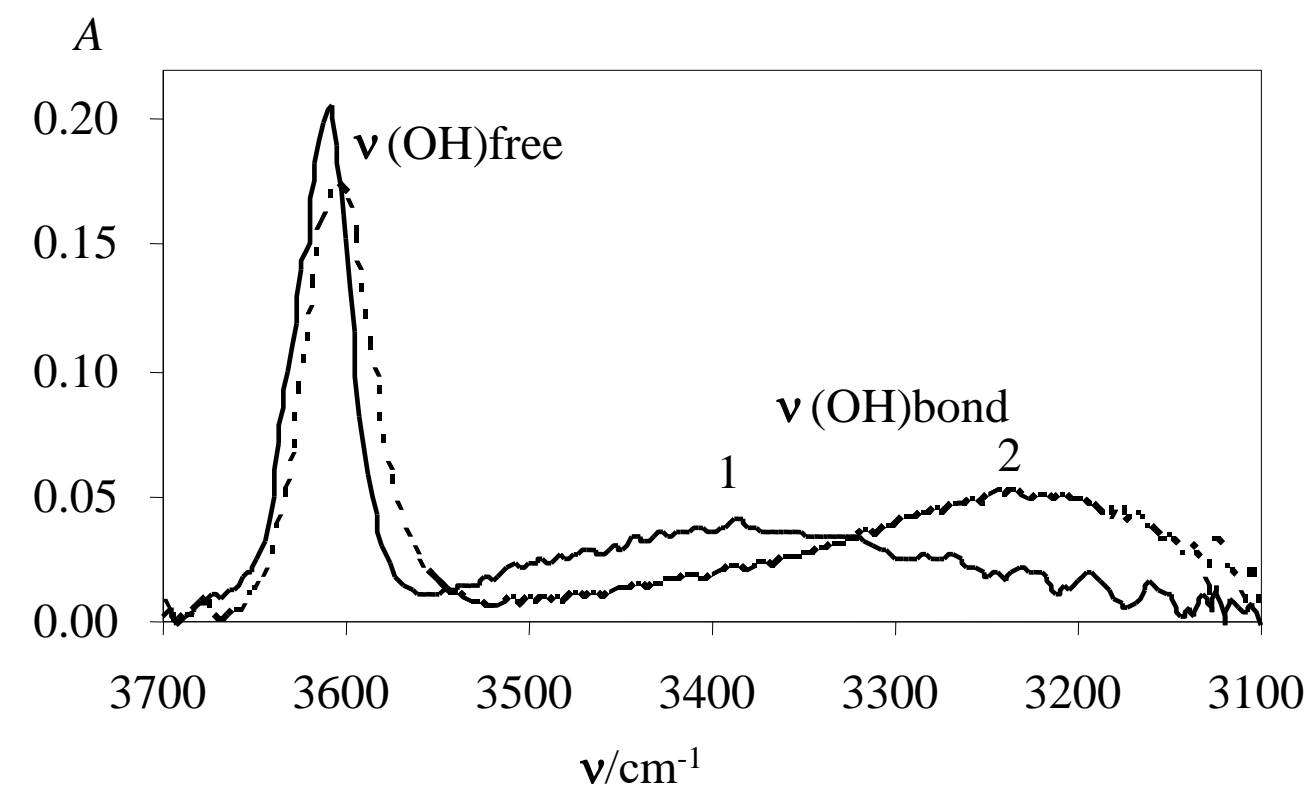

Figure 1

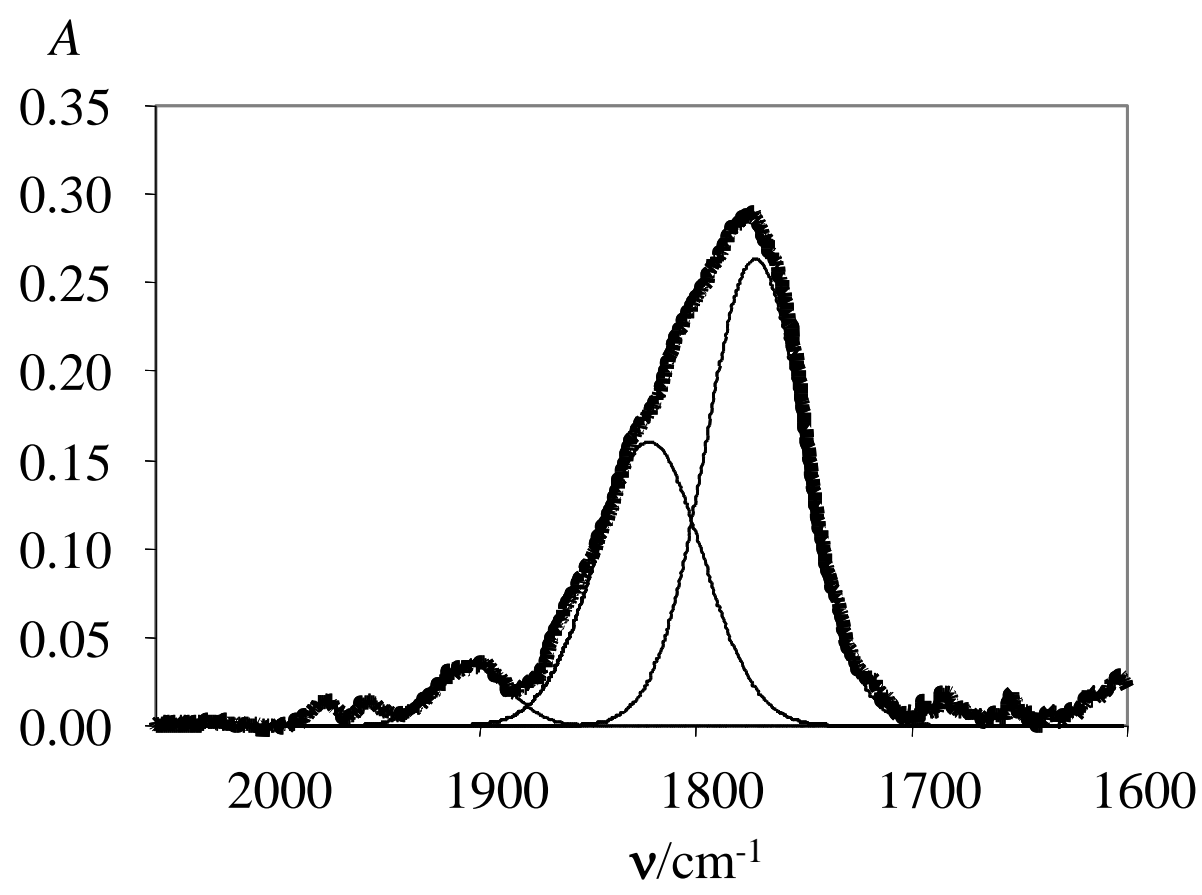

Figure 2 


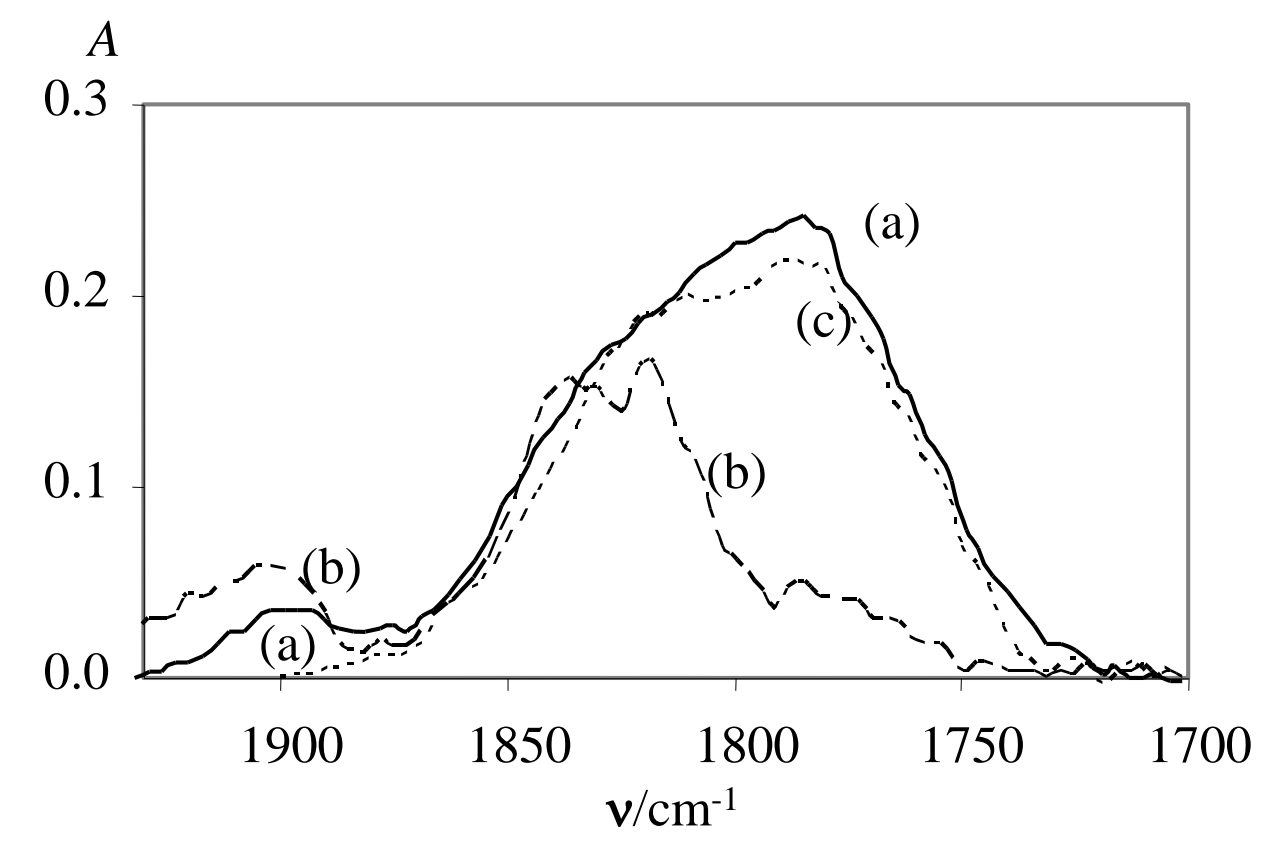

Figure 3

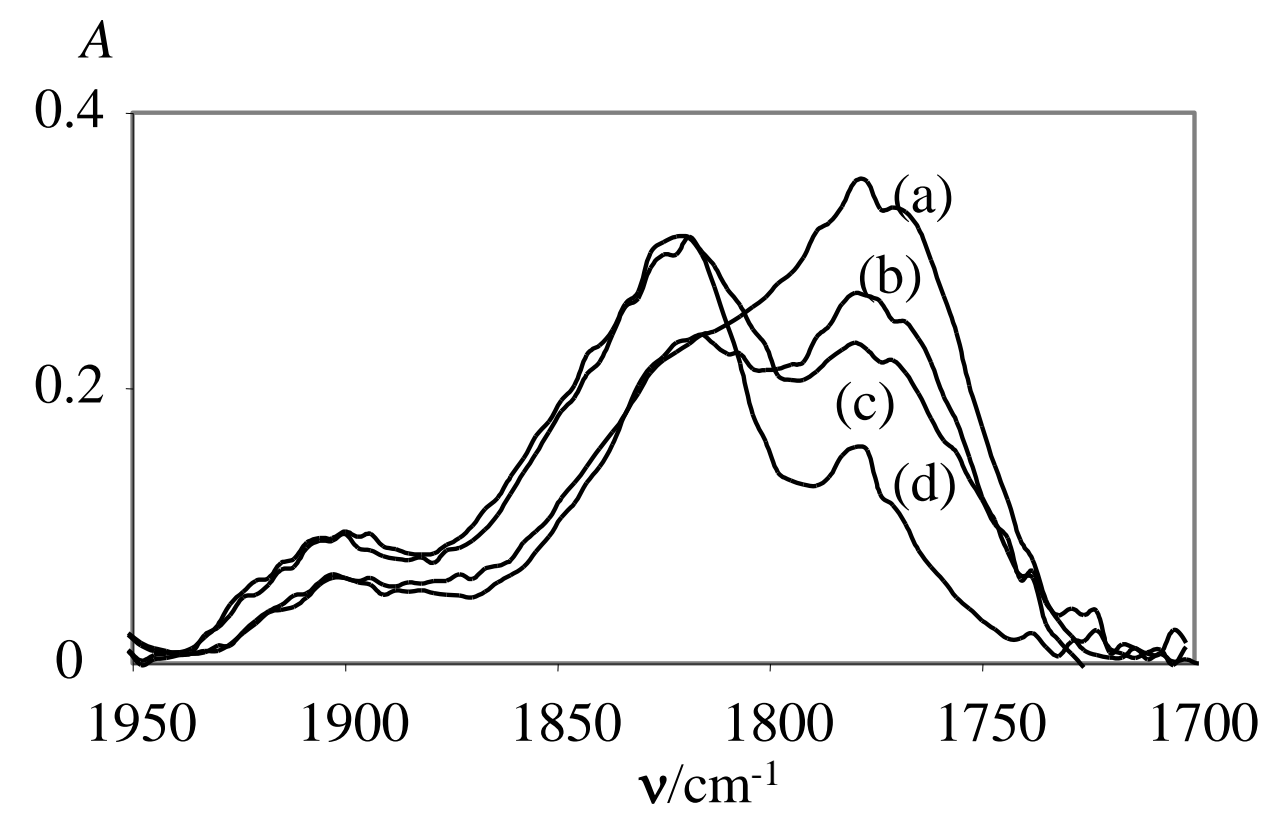

Figure 4 


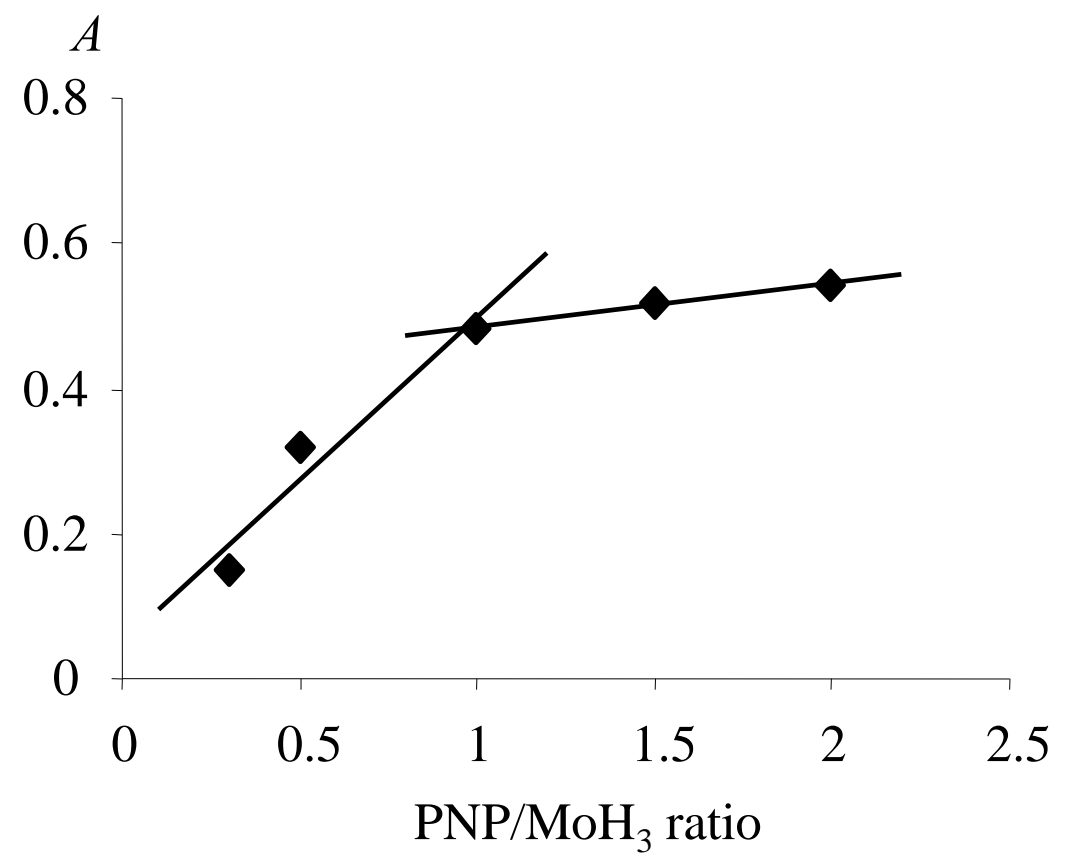

Figure 5

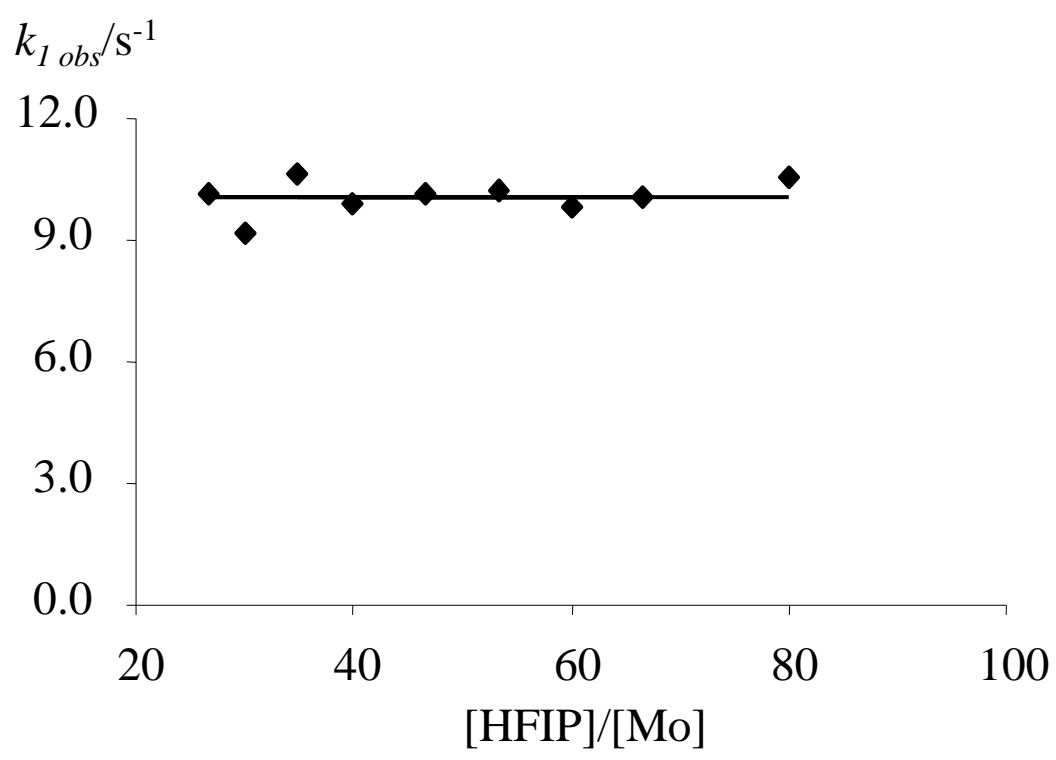

Figure 6 


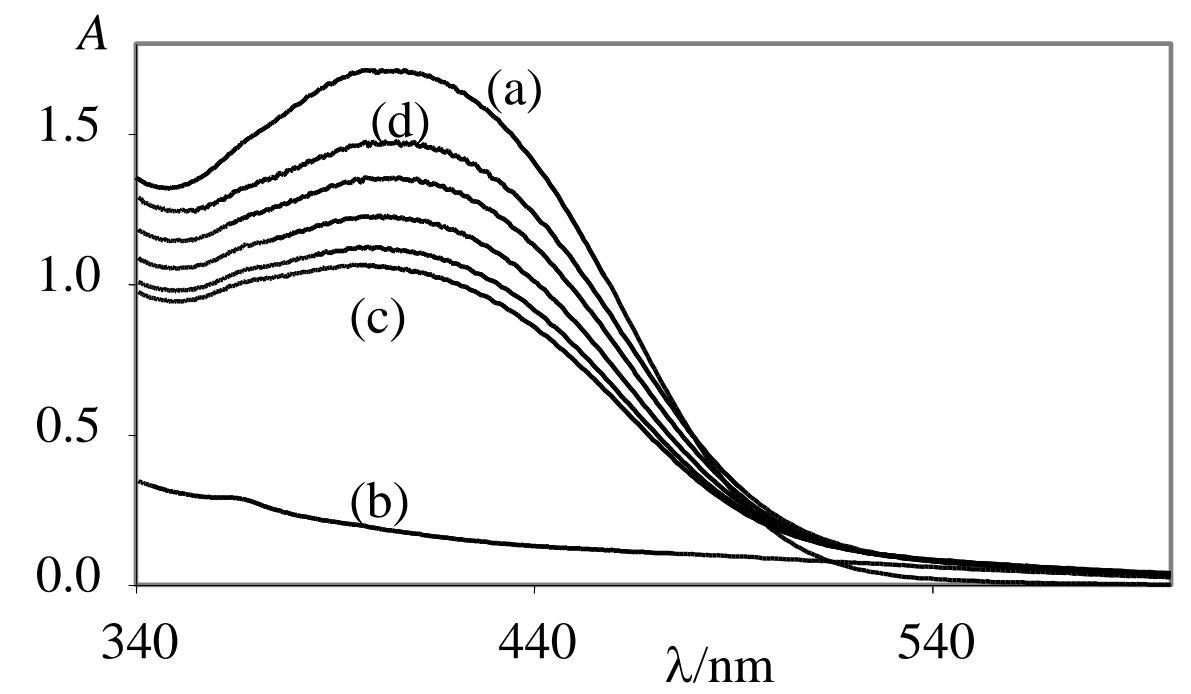

Figure 7
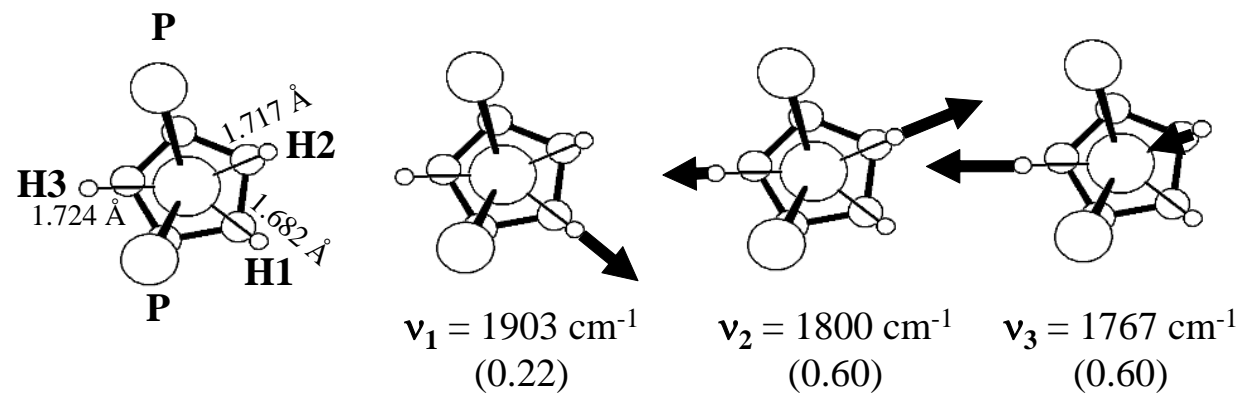

Figure 8 


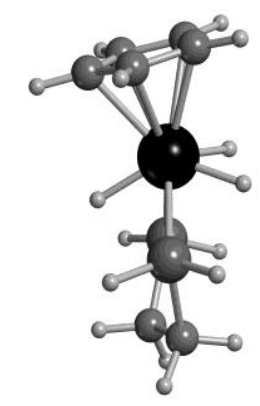

$\mathrm{CpMoH}_{3}$ (dhpe)

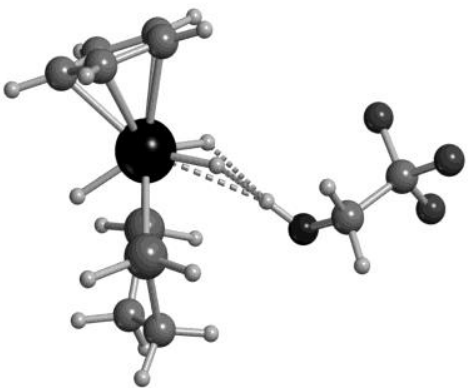

B1

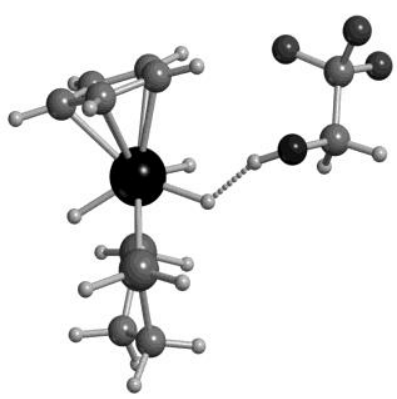

B3

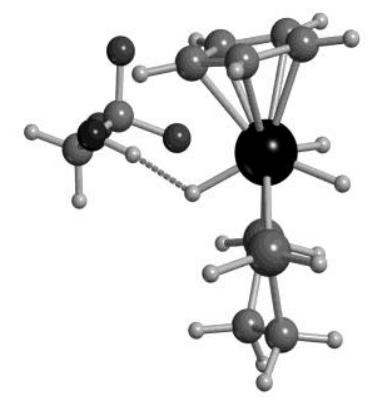

A

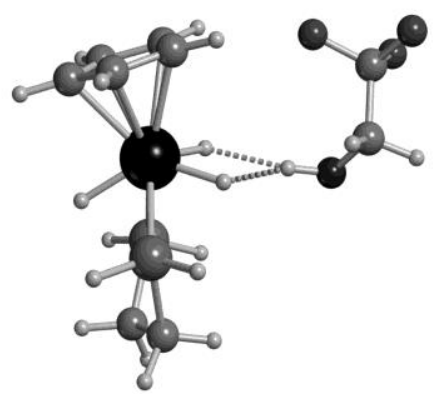

B2

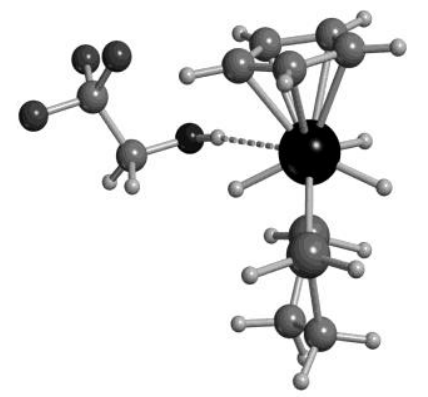

C

Figure 9 
(A)
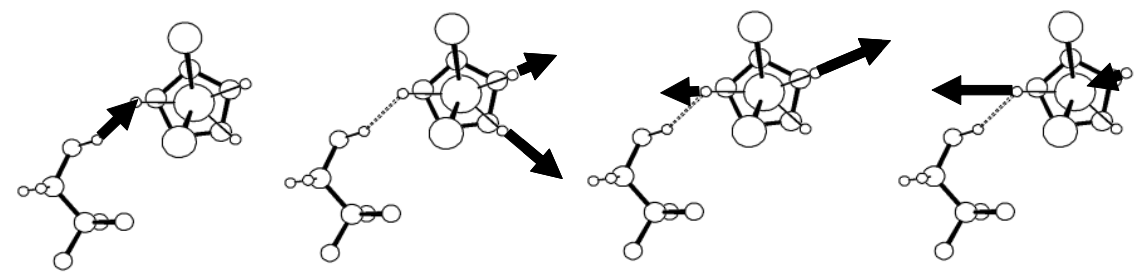

$v_{\mathrm{OH}}=3617 \mathrm{~cm}^{-1}$

(4.99)

$v_{1}=1920 \mathrm{~cm}^{-1}$

$v_{2}=1779 \mathrm{~cm}^{-1}$

$v_{3}=1746 \mathrm{~cm}^{-1}$

(0.63)

(1.28)

(B1)

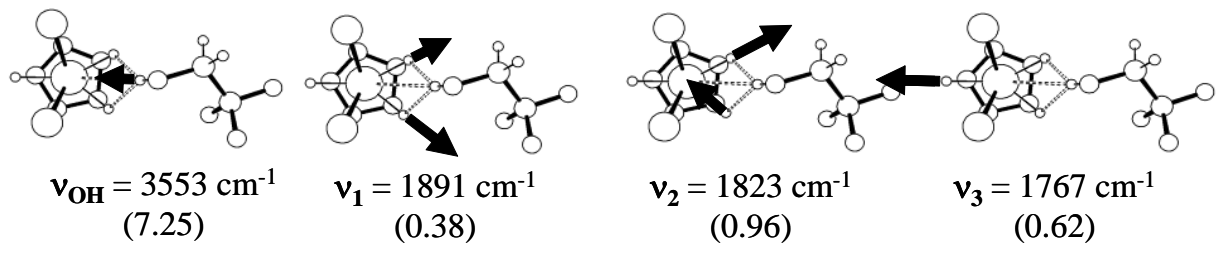

(B2)

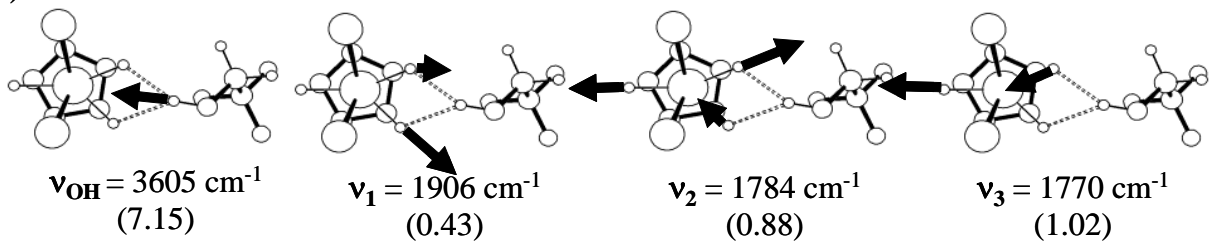

(B3)

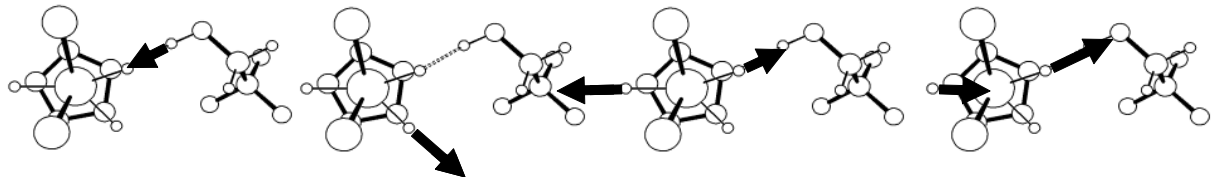

$$
\begin{array}{cccc}
v_{\text {OH }}=3552 \mathrm{~cm}^{-1} & v_{\mathbf{1}}=1907 \mathrm{~cm}^{-1} & v_{\mathbf{3}}=1784 \mathrm{~cm}^{-1} & \mathbf{v}_{\mathbf{2}}=1764 \mathrm{~cm}^{-1} \\
(7.77) & (0.26) & (0.38) & (2.21)
\end{array}
$$

(C)

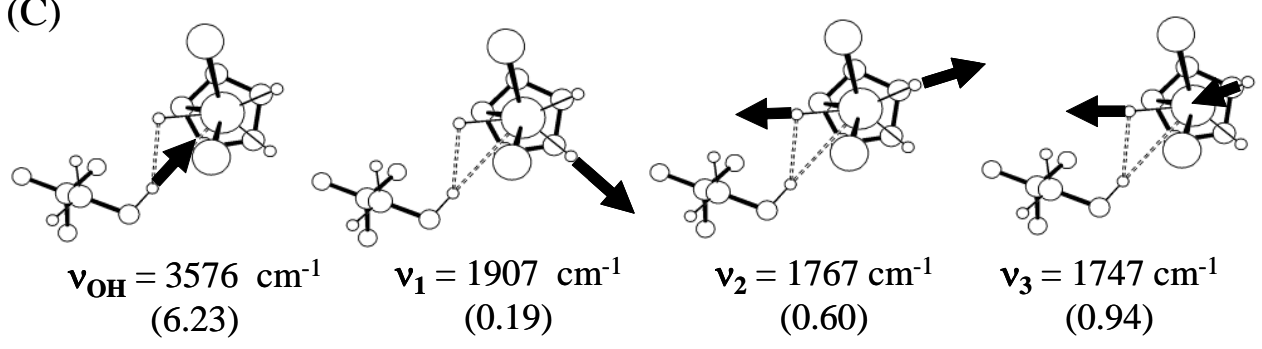

Figure 10 


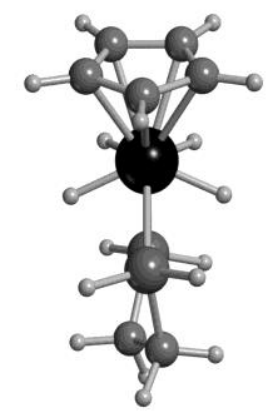

TETRA1

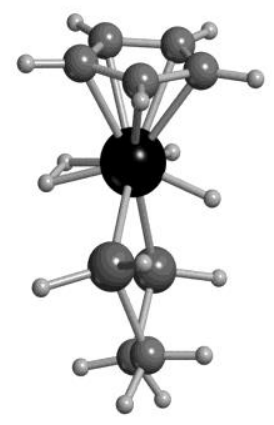

DIH1

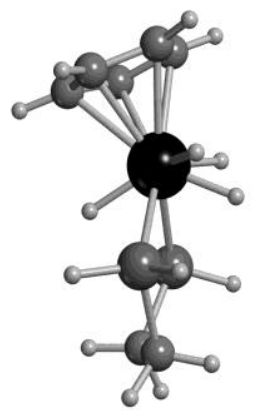

TETRA2

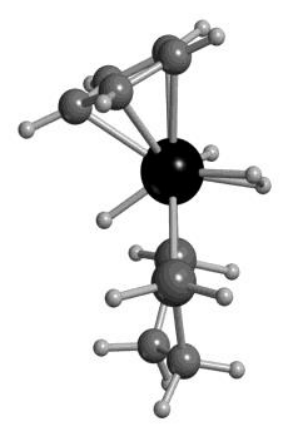

DIH2

Figure 11

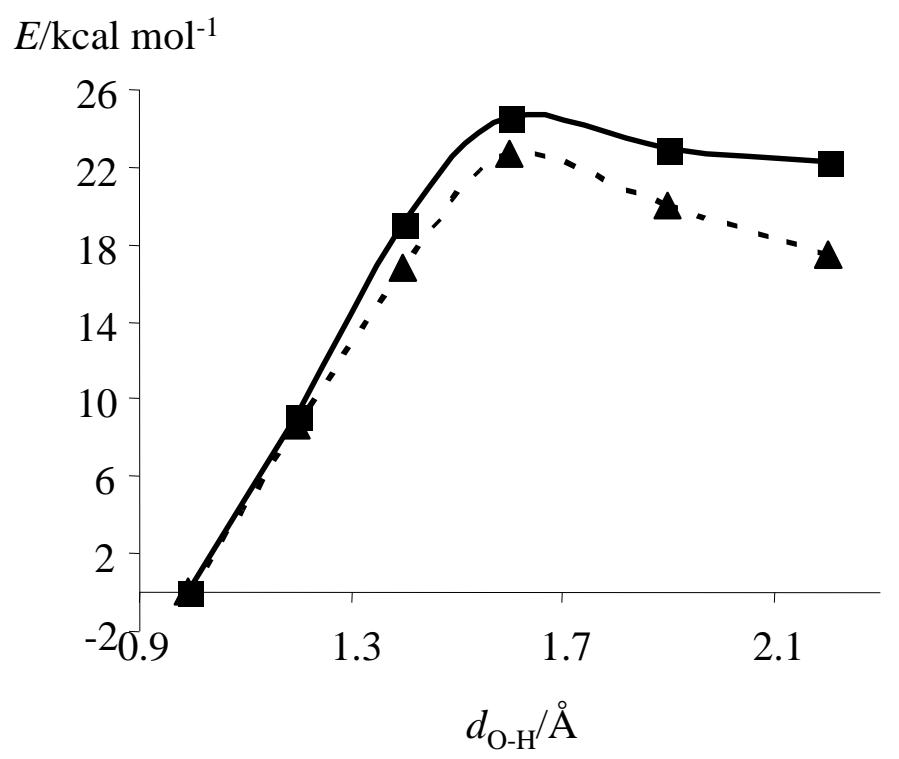

Figure 12 


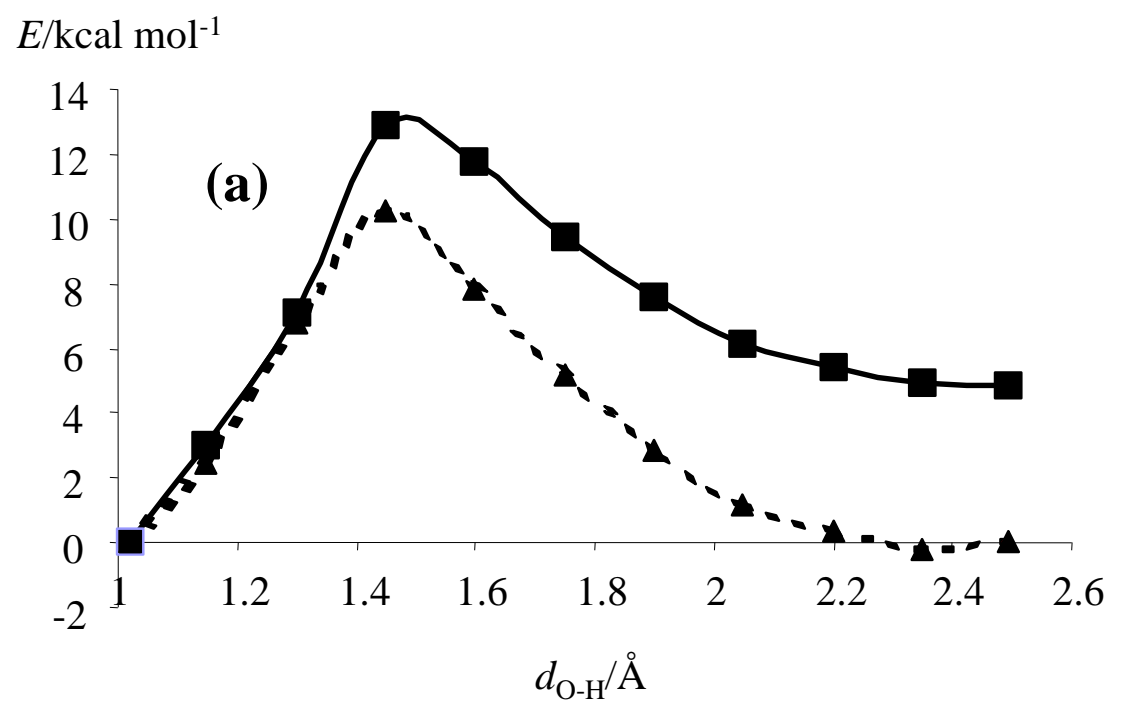

E/kcal mol-1

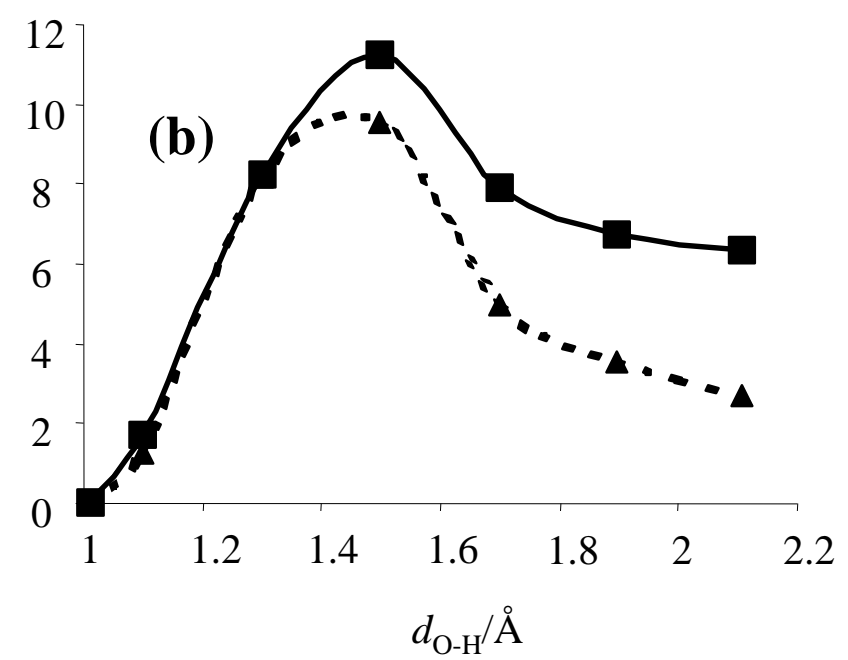

Figure 13

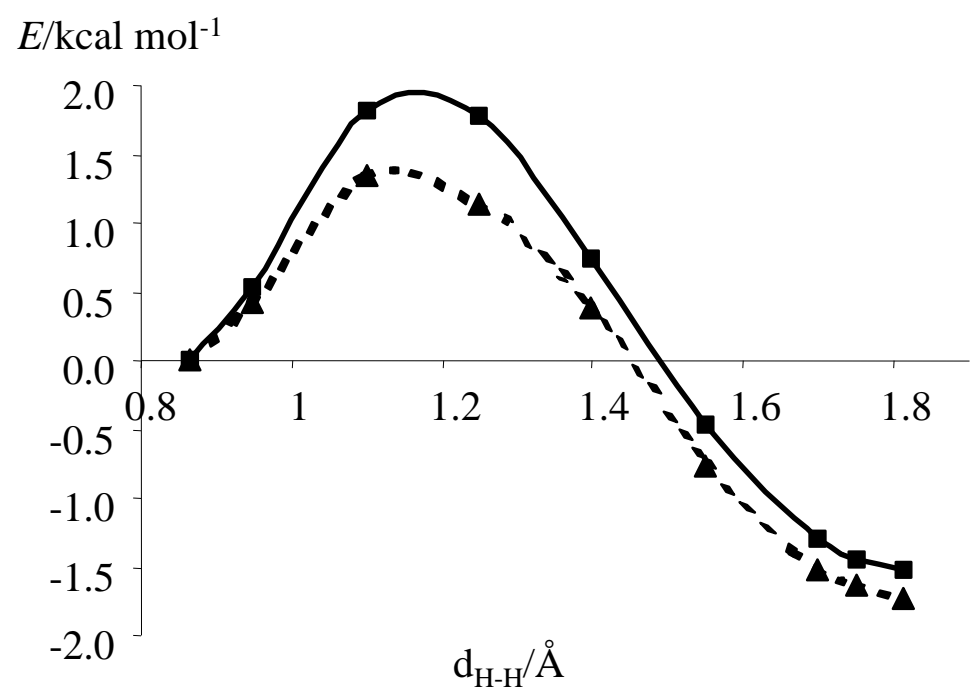

Figure 14 


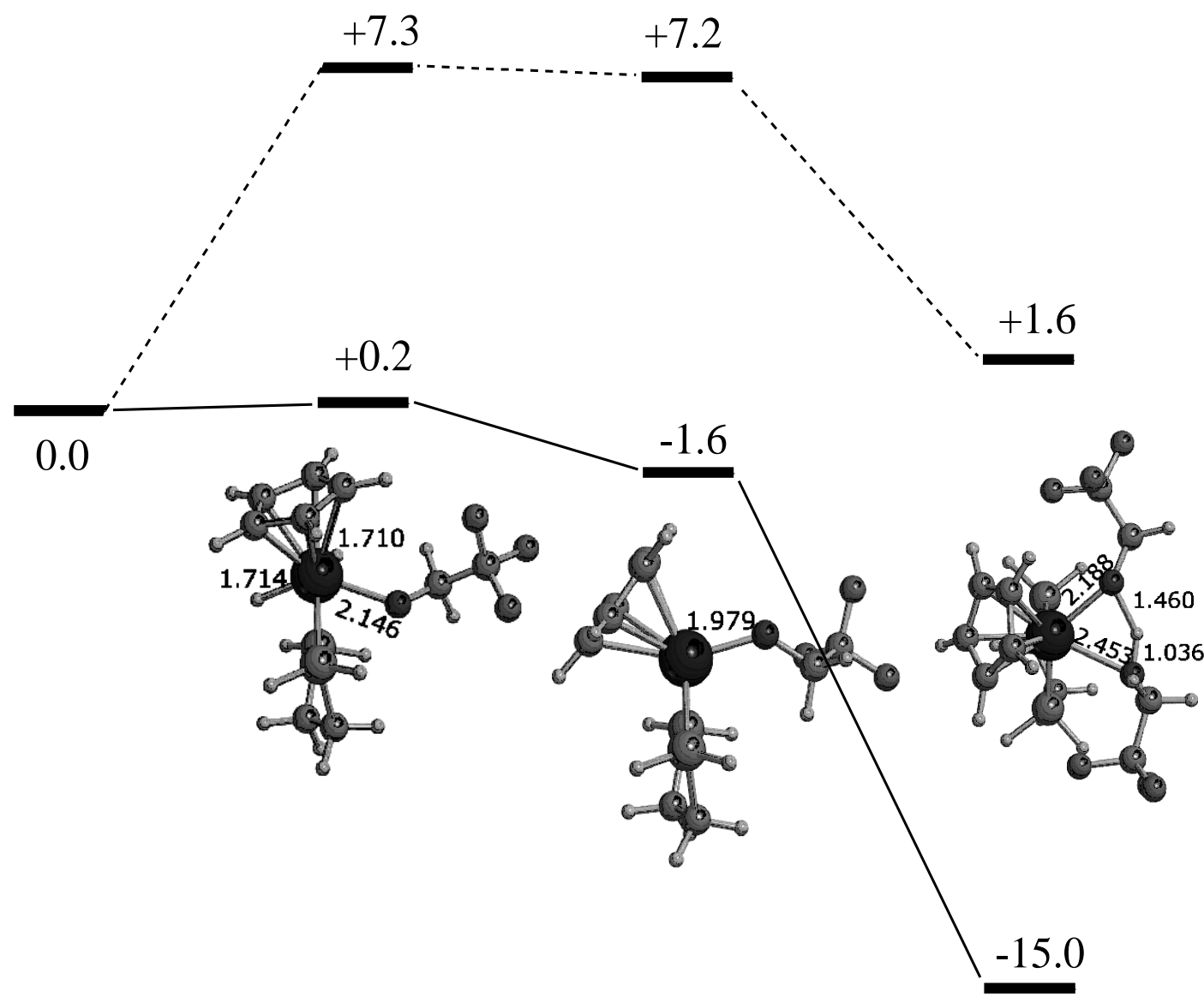

CpMo(dpe) $\mathrm{H}_{3}$ $\mathrm{CpMo}(\mathrm{dpe}) \mathrm{H}_{2}\left(\mathrm{OR}_{\mathrm{F}}\right)$ $+\mathrm{R}_{\mathrm{F}} \mathrm{OH}+\mathrm{H}_{2}$ $\mathrm{CpMo}(\mathrm{dpe})\left(\mathrm{OR}_{\mathrm{F}}\right)\left(\mathrm{R}_{\mathrm{F}} \mathrm{OH}\right)$ $+2 \mathrm{R}_{\mathrm{F}} \mathrm{OH}$

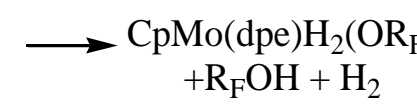
CpMo(dpe) $\left(\mathrm{OR}_{\mathrm{F}}\right)$ $+\mathrm{R}_{\mathrm{F}} \mathrm{OH}+2 \mathrm{H}_{2}$ $+2 \mathrm{H}_{2}$

Figure 15 
(b) Schemes

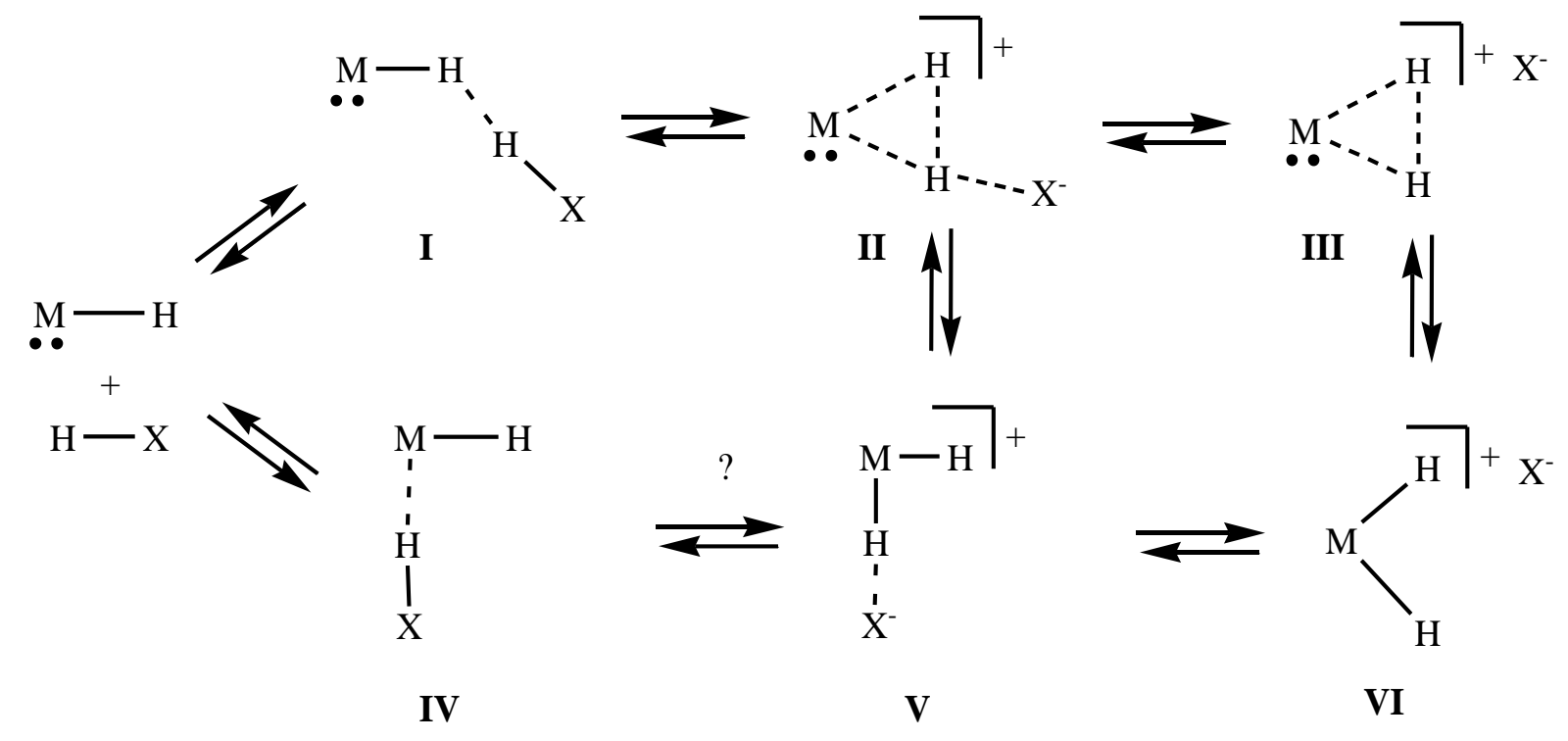

Scheme 1
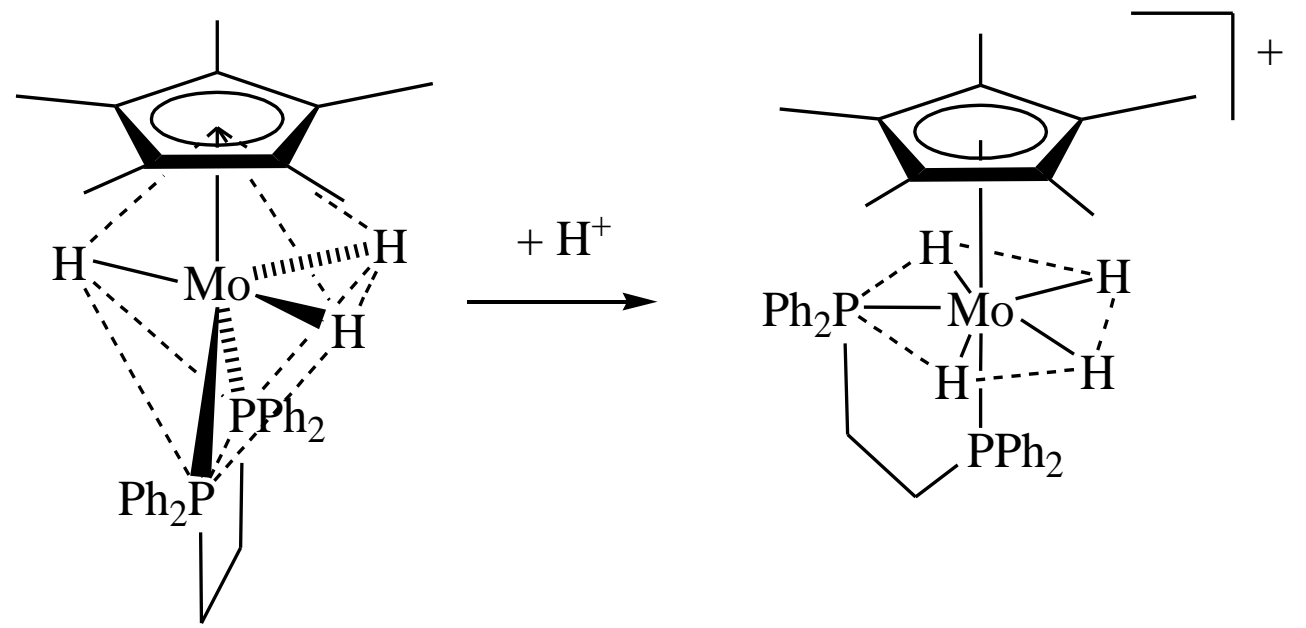

Scheme 2

$$
\begin{aligned}
& \mathrm{Cp} * \mathrm{Mo}(\text { dppe }) \mathrm{H}_{3}+\mathrm{R}_{\mathrm{F}} \mathrm{OH} \rightleftharpoons \mathrm{Cp}^{*} \mathrm{Mo}(\text { dppe }) \mathrm{H}_{3} \cdots \mathrm{HOR}_{\mathrm{F}} K_{\mathrm{HB}} \\
& \mathrm{Cp} * \mathrm{Mo}(\text { dppe }) \mathrm{H}_{3} \cdots \mathrm{HOR}_{\mathrm{F}} \rightleftharpoons\left[\mathrm{Cp} * \mathrm{Mo}(\text { dppe }) \mathrm{H}_{4}\right]^{+} \cdots \mathrm{OR}_{\mathrm{F}}^{-} \quad K_{\mathrm{PT}}=k_{1} / k_{-1}
\end{aligned}
$$

Scheme 3 


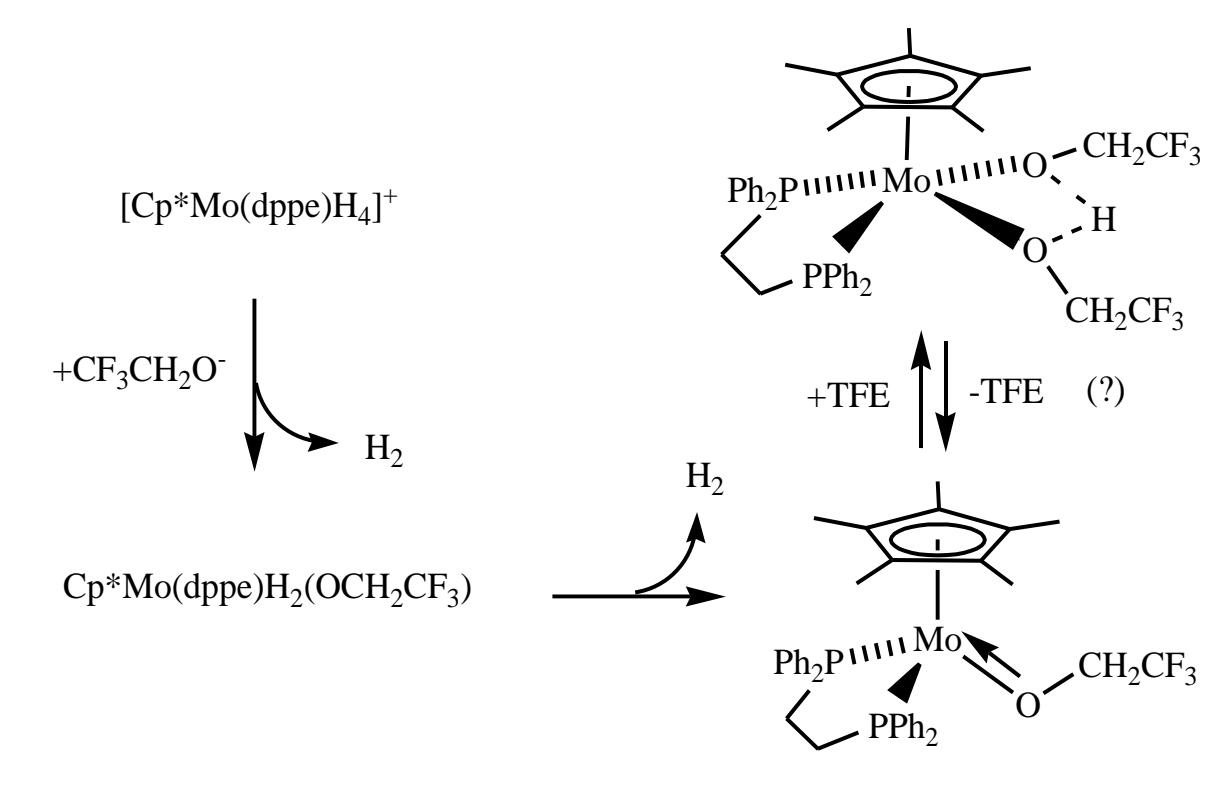

Scheme 4

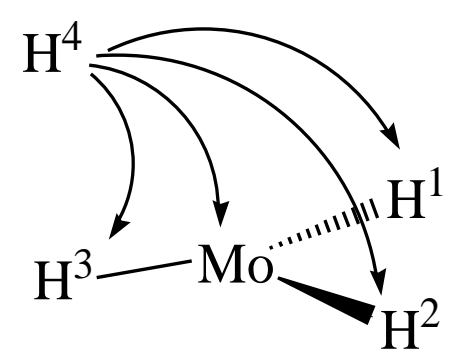

Scheme 5 


\section{(c) Equations}

$-\Delta \mathrm{H}_{\mathrm{HB}}=\frac{18 \Delta v}{\Delta v+720}$

Equation 1

$k_{\mathrm{obs}}=\frac{k_{1} K_{\mathrm{HB}}[\mathrm{HA}]}{1+K_{\mathrm{HB}}[\mathrm{HA}]}+k_{-1}$

Equation 2

$\Delta \mathrm{H}=2.9 \Delta \mathrm{A}^{1 / 2}=2.9\left(\mathrm{~A}^{1 / 2}\right.$ bonded $\left.-\mathrm{A}_{\text {free }}^{1 / 2}\right)$

Equation 3

$\left[[\mathrm{Mo}]-\mathrm{H}_{3}\right]+\mathrm{H}^{+} \rightarrow\left[[\mathrm{Mo}]-\mathrm{H}_{4}\right]^{+}$

Equation 4

$\left[\mathrm{CpMoH}_{3}(\mathrm{dpe}) \cdots \mathrm{HOCH}\left(\mathrm{CF}_{3}\right)_{2}\right]+\left(\mathrm{CF}_{3}\right)_{2} \mathrm{CHOH} \rightarrow$

$\left.[\mathrm{CpMo}(\mathrm{dpe}))^{\prime \prime} \mathrm{H}_{4}{ }^{\prime}\right]^{+} \cdot\left[\left(\mathrm{CF}_{3}\right)_{2} \mathrm{CHO} \cdots \mathrm{H} \cdots \mathrm{O}-\mathrm{CH}\left(\mathrm{CF}_{3}\right)_{2}\right]^{-}$

Equation 5 
(d) Table of Contents Entry

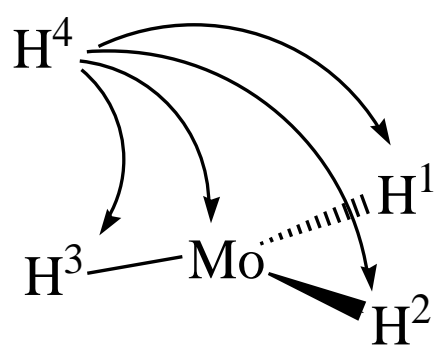


